Research Article

\title{
Distribution and Variation of Mining-Induced Stress in the Reverse Fault-Affected Coal Body
}

\author{
Rui Zhou, ${ }^{1,2,3}$ Yujin Qin $\mathbb{D}^{1,2}$ and Zhizhen Zhang $\mathbb{D}^{2,4}$ \\ ${ }^{1}$ China Coal Technology Engineering Group Shenyang Research Institute, Fushun 113122, China \\ ${ }^{2}$ State Key Laboratory of Coal Mine Safety Technology, Fushun 113122, China \\ ${ }^{3}$ Key Laboratory of Ministry of Education on Safe Mining of Deep Metal Mines, Northeastern University, \\ Shenyang 110819, China \\ ${ }^{4}$ State Key Laboratory of Geomechanics and Deep Underground Engineering, School of Mechanics and Civil Engineering, \\ China University of Mining and Technology, Xuzhou 221116, China
}

Correspondence should be addressed to Yujin Qin; 359240092@qq.com and Zhizhen Zhang; zzzhang@cumt.edu.cn

Received 1 February 2021; Revised 14 March 2021; Accepted 17 April 2021; Published 29 April 2021

Academic Editor: Sanjay Nimbalkar

Copyright (c) 2021 Rui Zhou et al. This is an open access article distributed under the Creative Commons Attribution License, which permits unrestricted use, distribution, and reproduction in any medium, provided the original work is properly cited.

This study aimed to explore the stress distribution and variation of reverse fault-affected mined coal body. A mechanical analysis model of the coal body in the reverse fault area was first established, then the coal body stress characterization equation was derived, and the stress distribution pattern on the coal body was calculated. Subsequently, applying the Mohr-Coulomb strength criterion revealed the following relationship: the closer is the distance to the reverse fault, the worse is the stability of the coal body, and that the coal body strength influences the stress concentration of the coal body in front of the working face. Moreover, simulation with FLAC $^{3 \mathrm{D}}$ was carried out to verify the coal body stress calculated by the mechanical model as well as the fluctuation of the coal body stress concentration. It could be concluded that while mining the hanging wall of the reverse fault, the stress concentration of mined coal body decreases with the increase of reverse fault dip angle, but increases with the increase of reverse fault throw; the stress concentration magnitude generated during footwall mining is lesser than that during hanging-wall mining. In other words, the magnitude of coal body stress concentration can be affected by the hanging wall and footwall mining, as well as parameters of the reverse fault. Finally, intrinsically safe GZY25 borehole stress sensors were used to monitor the coal body stresses in the reverse fault area under the influence of mining in Xinchun Coal Mine and ZuoQiuka Coal Mine. It was found that the coal body stress concentration in front of the working face either increased gradually or increased first before decreasing. It can be concluded that with the decrease of the distance between the working face and reverse fault, the vertical stress of the coal body increases, and the vertical stress of the coal body begins to increase obviously at a certain position. At this point, the vertical stress of the coal body can be generalized to 1.02-1.39 times of the initial vertical stress. Furthermore, the stress concentration coefficient of coal body is related to the distance from the reverse fault, and two changes occur: (1) if the coal-bearing capacity does not exceed its strength, the coal stress in front of the working face increases gradually, and the stress concentration factor increases gradually; (2) the stress concentration coefficient of mining coal body increases first, such that when the coal body bearing capacity exceeds its strength, the coal body fails and loses all its effective bearing capacity, followed by the decrease in coal body stress concentration coefficient.

\section{Introduction}

Reverse faults are common geological structures widely distributed in China's coal-producing areas [1-3], especially those in the southwest of the country, such as Guizhou, Yunnan, and Sichuan. Underground coal mine projects in these areas often take place across or close to these reverse faults [4-6]. In fact, the coal bodies often lose their stability when the mining face gets too close to the reverse fault [7-11]. Also, reverse faults have sealing properties, so mining stress will also have an impact on gas bearing and its migration. Therefore, the mining activities in the reverse 
fault area inflict massive challenges to the site construction and maintenance [12-14]. To ensure safety and improve mining productivity around the coal seam in the reverse fault area, it is necessary to study the stress variation trend of reverse fault-affected mined coal bodies.

At present, significant achievements have been made in the analysis of mined coal body stress in reverse fault regions. However, due to high susceptibility to rockbursts caused by the mining conditions-incurred reverse fault instability, plenty of research efforts have been focused on fields related to the prevention of rockbursts, such as stress variation, the stability of reverse fault zone, and the slip of reverse fault zone. To clarify the stress variation characteristics of reverse fault-affected mined coal bodies and explore the stress distribution characteristics of the mined coal bodies under various working faces, reverse fault distances, reverse fault dip angles, and fault throws, the actual working conditions of a typical working face in Guizhou mining area, were taken as the reference for the research herein.

\section{Mechanical Model of the Reverse Fault- Affected Mined Coal Body}

2.1. Theoretical Model. To study the stress distribution characteristics of the reverse fault-affected mined coal body, we established a geomechanical analysis model for coal rocks, measuring $H$ and $L$ along the $X$ and $Y$ axes respectively, as shown in Figure 1. A reverse fault was designed in front of the mining face, and $\mathrm{O}$ marks the intersection point of the reverse fault and the roof of the coal seam. It is vertically subject to the stress of the overburden above the roof of the coal seam and horizontally to the horizontal stress. Under normal circumstances, the horizontal and vertical stresses are approximately equal, but due to the existence of a reverse fault, the horizontal compression should become obvious in actuality, so the horizontal stress is set herein as 1.5 times the vertical stress [4]. With the advancement of the mining face, the upper roof becomes an area subject to abutment stresses of various magnitudes and the front side of the working face and the rear side of the goaf become areas subject to increasing levels of abutment stress, whereas the goaf turns into an area subject to decreasing levels of abutment stress. With the advancement of the working face, the scope of the abutment stress also changes. Since hanging walls serve as the active plates in reverse faults, the effects of all mechanical stresses will also become more obvious. For this reason, the mining activities on the hanging wall of the reverse fault are taken as the object of mechanical analysis herein [15].

According to the distribution law of mine pressure [16], the vertical stress of roof can be divided into eight areas, the maximum stress value of $\mathrm{AB}$ and $\mathrm{BC}$ is $K_{1} \cdot q_{x}$, the maximum stress value of FG and $\mathrm{GH}$ is $K_{3} \cdot q_{x}$, the maximum stress value of $\mathrm{CD}$ and $\mathrm{DF}$ is $K_{2} \cdot q_{x}$, and the stress value of $\mathrm{OA}$ and $\mathrm{HJ}$ is $q_{x}$.

The stress in the horizontal direction is $q_{y}$, according to the boundary conditions of the mechanical analysis model of reverse fault, the horizontal stress is $1.5 q_{x}[4,12]$. In order to quantitatively calculate the law of coal stress variation, the vertical stress variation curve of roof stress support area is simplified as linear variation.

In the analysis process, it is assumed that the coal geological body is homogeneous and isotropic. According to rock mechanics [16], the concentrated force $P$ acting on the plane will affect any point $M(x, y)$ below the plane, and its vertical stress value can be expressed as

$$
\sigma_{x}=-\frac{2 P}{\pi} \cdot \frac{x^{3}}{\left(x^{2}+y^{2}\right)^{2}} .
$$

Therefore, under the combined action of horizontal stress and vertical stress in the reverse fault-affected area, the vertical stress of $M(x, y)$ can be expressed as

$$
\begin{aligned}
\sigma_{x}= & \frac{-2}{\pi} \cdot \int_{0}^{a} \frac{q_{x} \cdot x^{3}}{\left[x^{2}+(y-\xi)^{2}\right]^{2}} d \xi+\frac{-2}{\pi} \cdot \int_{a}^{b} \frac{\left(\left(\left(q_{x}-K_{1} \cdot q_{x}\right) /(a-b)\right) \cdot y-\left(\left(b \cdot q_{x}-a \cdot K_{1} \cdot q_{x}\right) / a-b\right)\right) \cdot x^{3}}{\left[x^{2}+(y-\xi)^{2}\right]^{2}} d \xi \\
& +\frac{-2}{\pi} \cdot \int_{b}^{c} \frac{\left(K_{1} \cdot q_{x} /(b-c) \cdot y-\left(c \cdot K_{1} \cdot q_{x} /(b-c)\right)\right) \cdot x^{3}}{\left[x^{2}+(y-\xi)^{2}\right]^{2}} d \xi \\
& +\frac{-2}{\pi} \cdot \int_{c}^{d} \frac{\left(-\left(K_{2} \cdot q_{x} /(c-d)\right) \cdot y+\left(c \cdot K_{2} \cdot q_{x} /(c-d)\right)\right) \cdot x^{3}}{\left[x^{2}+(y-\xi)^{2}\right]^{2}} d \xi+\frac{-2}{\pi} \cdot \int_{d}^{f} \frac{K_{2} \cdot q_{x} \cdot x^{3}}{\left[x^{2}+(y-\xi)^{2}\right]^{2}} d \xi \\
& +\frac{-2}{\pi} \cdot \int_{f}^{g} \frac{\left(-\left(q_{x}-K_{2} \cdot q_{x} /(f-g)\right) \cdot y-f \cdot q_{x}-g \cdot K_{2} \cdot q_{x} /(f-g)\right) \cdot x^{3}}{\left[x^{2}+(y-\xi)^{2}\right]^{2}} d \xi \\
& +\frac{-2}{\pi} \cdot \int_{g}^{h} \frac{\left(-\left(q_{x}-K_{3} \cdot q_{x} /(g-h)\right) \cdot y+\left(g \cdot q_{x}-h \cdot K_{3} \cdot q_{x} /(g-h)\right)\right) \cdot x^{3}}{\left[x^{2}+(y-\xi)^{2}\right]^{2}} d \xi+\frac{-2}{\pi} \cdot \int_{h}^{j} \frac{q_{x} \cdot x^{3}}{\left[x^{2}+(y-\xi)^{2}\right]^{2}} d \xi \\
& +\frac{-2}{\pi} \cdot \int_{0}^{H} \frac{q_{y} \cdot y^{3}}{\left[y^{2}+(y-\xi)^{2}\right]^{2}} d \xi, \quad
\end{aligned}
$$




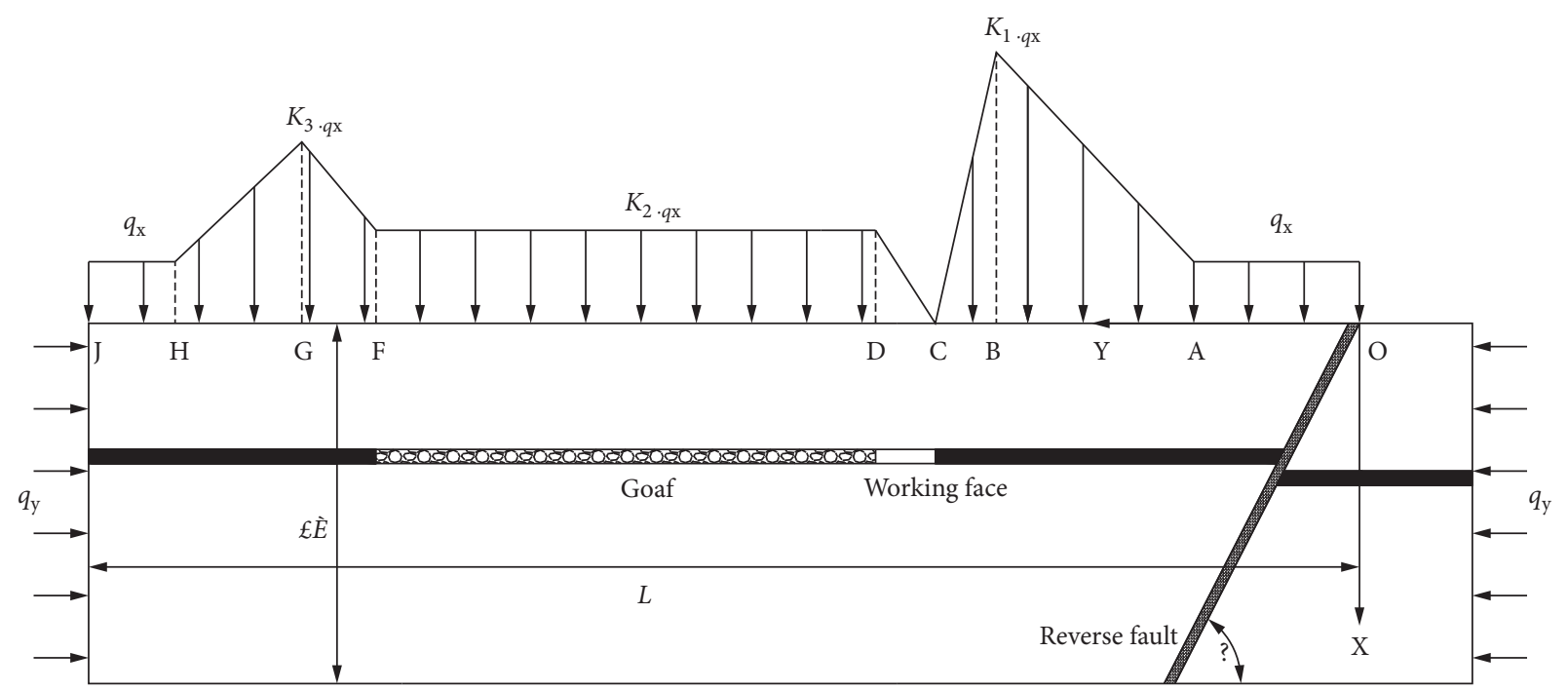

FIGURE 1: Mechanical model of mining coal under the influence of reverse fault.

where $q_{x}$ is the vertical stress, $\mathrm{MPa} ; q_{\mathrm{y}}$ is the horizontal stress, $\mathrm{MPa}$; A, B, C, D, F, G, H, and J are $Y$-axis lengths, and $K_{1}, K_{2}$, and $K_{3}$ are stress concentration factors.

When the coal load exceeds its strength, the coal body will undergo plastic deformation and fails, which leads to a reduction in stress. In view of this, the Mohr-Coulomb strength criterion was applied to analyze the stability of the coal body and determine whether failure occurs (see Equation (3)), before analyzing its stress characteristics.

$$
\begin{cases}\frac{\sigma_{1}-\sigma_{3}}{\sigma_{1}+\sigma_{3}+2 \cot \phi}<\sin \phi, & \text { stability, } \\ \frac{\sigma_{1}-\sigma_{3}}{\sigma_{1}+\sigma_{3}+2 \cot \phi}=\sin \phi, & \text { limit equilibrium, } \\ \frac{\sigma_{1}-\sigma_{3}}{\sigma_{1}+\sigma_{3}+2 \cot \phi}>\sin \phi, & \text { instability, }\end{cases}
$$

where $\sigma_{1}$ is the first principal stress, $\mathrm{MPa} ; \sigma_{3}$ is the third principal stress, $\mathrm{MPa} ; \varphi$ is the friction angle in coal body.

While mining the working face, shear stresses on mined coal bodies are relatively negligible in magnitude compared with the vertical and horizontal stresses, which makes it reasonable to omit their contributions in calculations. In fact, vertical stress of the coal body is generally taken as the first principal stress and the horizontal stress of working face inclination as the third principal stress [17]. With the decrease of the distance between working face and reverse fault, the stress concentration magnitude of coal body in front of working face and $\sigma_{1}$ increase gradually. $\sigma_{3}$ is influenced by the mining roadway on both sides of the working face, so stress will not be concentrated during mining activities. Moreover, when the position of coal body in front of the working face and the working face is the same, the difference in $\sigma_{3}$ is not large and hence can be simplified as equal. As such, Equation (3) $\left(\sigma_{1}-s \sigma_{3}\right) /\left(\sigma_{1}+\sigma_{3}+2 \cot \varphi\right)$ can be converted into $1-\left(\left(2 \sigma_{3}+2 \cot \varphi\right) /\left(\sigma_{1}+\sigma_{3}+2\right.\right.$ $\cot \varphi)$ ), whose value increases gradually with the increase of $\sigma_{1}$. This implies that $\left(\sigma_{1}-\sigma_{3}\right) /\left(\sigma_{1}+\sigma_{3}+2 \cot \varphi\right)$ also increases gradually, which in turn indicates that, as the mining activity on the working face proceeds, the stability of mining-induced coal decreases gradually; when the coalbearing capacity exceeds its strength, the coal will undergo plastic deformation and fails, resulting in the reduction of coal stress. The same can be inferred that, as the mining activity proceeds along the direction of the working face to the reverse fault, if the coal-bearing capacity does not exceed its strength, the coal body stress in front of the working face will increase, and the stress concentration coefficient will gradually increase; if the bearing capacity of the coal body exceeds its strength, the coal pillar between the working face and the reverse fault will fail, and the coal body will effectively lose the capacity to bear the load inflicted on it, hence lowering the stress concentration coefficient of the coal body in front of the working face.

\subsection{Mechanical Calculations Associated with the Reverse} Fault-Affected Mined Coal Body. Xinchun Coal Mine is located in the west of Tongzi County, Guizhou Province, with a designed production capacity of 900,000 t/a and service life of $62 \mathrm{a}$. The 1503 working face is located in the southeast of the mine.

The C5 coal seam has been mined to a depth of 300-420 $\mathrm{m}$ using the strike longwall mining method. In the mining area of the 1503 working face, there lies the F4 reverse fault, which has a fault dip angle of $60^{\circ}$, length of $195 \mathrm{~m}$, fault spacing of $0-6 \mathrm{~m}$, and average length of $4 \mathrm{~m}$. There is no other structure in the mining area of the 1503 working face; the working face layout is as illustrated in Figure 2.

To get a clearer understanding of the mechanical distribution characteristics of the reverse fault-affected mined coal body, the required calculation parameters were selected from the field geological conditions of Xinchun Coal Mine: 


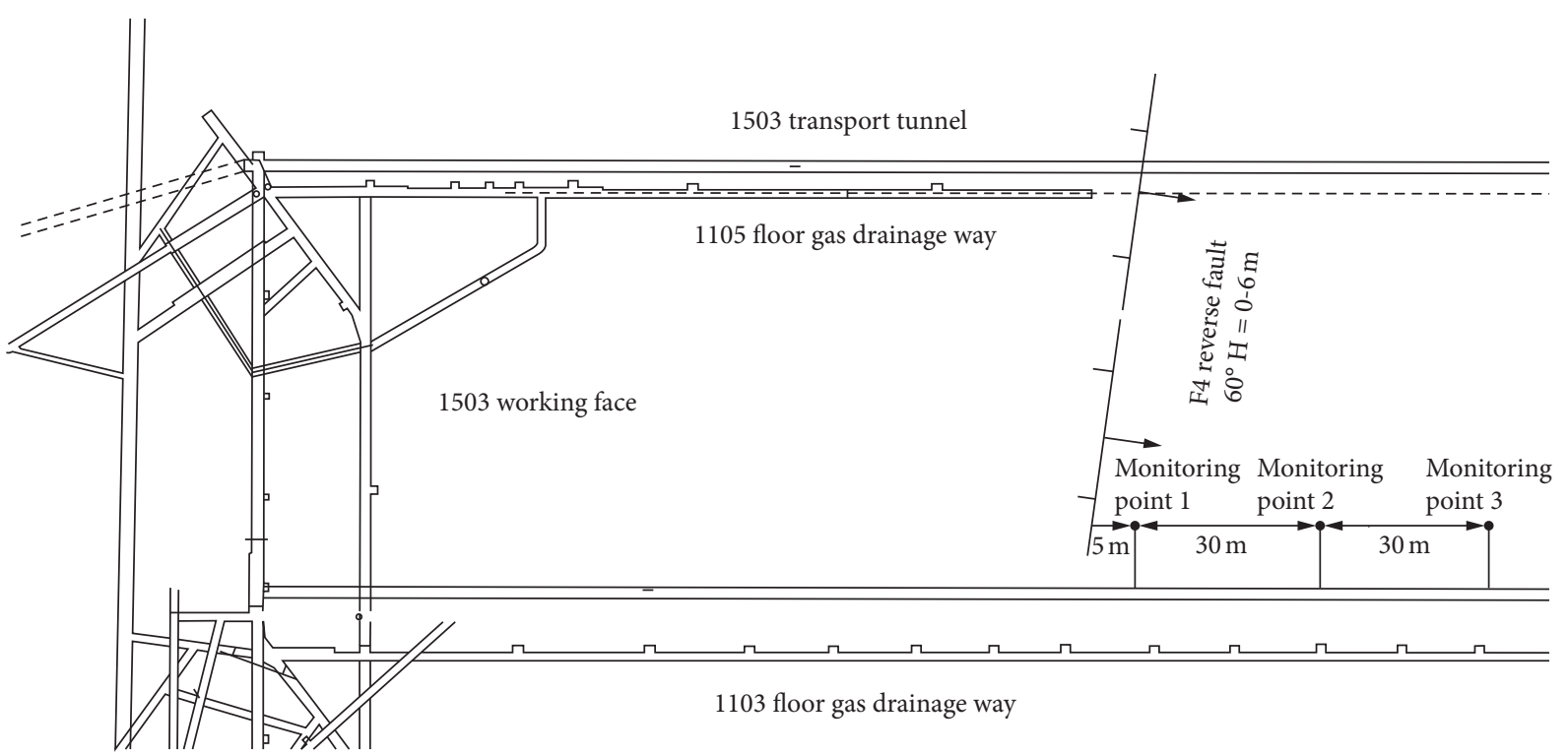

Figure 2: Map of 1503 working face.

vertical stress $q_{x}=9.0 \mathrm{MPa}$, horizontal stress $q_{y}=13.5 \mathrm{MPa}$, the distance between the coal seam and the roof $=9 \mathrm{~m}$, and the mining height of the coal seam $=2.0 \mathrm{~m}$. Relevant principles of mining science were consulted to determine the selection range of each stress zone, while a field investigation was conducted to determine specific parameters. Starting from a working face position separated by $70 \mathrm{~m}$ from the reverse fault, the distance parameter $\mathrm{OA}$ is $57 \mathrm{~m}, \mathrm{AB}$ is $28 \mathrm{~m}$, BC is $2 \mathrm{~m}, \mathrm{CD}$ is $4 \mathrm{~m}, \mathrm{DF}$ is $100 \mathrm{~m}, \mathrm{FG}$ is $2 \mathrm{~m}, \mathrm{Hg}$ is $28 \mathrm{~m}, K_{1}$ is $2.3, K_{2}$ is 0.8 , and $K_{3}$ is 2.0 . Substituting relevant parameters into (2), the vertical stress distribution curve of the mined coal body is calculated at various working face positions from the reverse fault, as shown in Figure 3.

When the distance between the working face and the reverse fault is $70 \mathrm{~m}, 40 \mathrm{~m}$, and $10 \mathrm{~m}$, respectively, there is a stress concentration area in front of the working face, and the coal body stress rises, and the vertical stress of the coal body reaches the maximum at $5 \mathrm{~m}$ in front of the working face. After that, the coal body stress begins to decline and gradually returns to the original stress state after exceeding the influence range of the stress increase area. By calculation, the maximum vertical stress of coal body in front of working face is $15.82 \mathrm{MPa}$ and the stress concentration coefficient is 1.58 when the distance from the reverse fault is $70 \mathrm{~m}$; when the distance from the reverse fault is $40 \mathrm{~m}$, the maximum vertical stress of the coal body is $16.43 \mathrm{MPa}$, and the stress concentration coefficient is 1.64; when the distance from the reverse fault is $10 \mathrm{~m}$, the maximum vertical stress of the coal body is $18.52 \mathrm{MPa}$, and the stress concentration coefficient is 1.85. It is found that with the decrease of the distance between the working face and the reverse fault, the stress concentration degree of the coal body in front of the working face increases, and the maximum value of the vertical stress increases.

When the distance between the working face and the reverse fault is $70 \mathrm{~m}, 40 \mathrm{~m}$, and $10 \mathrm{~m}$, respectively, stress concentration areas are formed in front of the respective working faces. In these areas, the coal body stress rises and the vertical stress of the coal body reaches its maximum at $5 \mathrm{~m}$ in front of the working face. After that, the coal body stress begins to decline and gradually returns to the original stress state after exceeding the influence range of the stress increase area. According to the calculation, the maximum vertical stress of the coal body in front of the working face is $15.82 \mathrm{MPa}$ and the stress concentration coefficient is 1.58 when the distance from the reverse fault is $70 \mathrm{~m}$. When the distance from the reverse fault is $40 \mathrm{~m}$, the maximum vertical stress of the coal body is $16.43 \mathrm{MPa}$, and the stress concentration coefficient is 1.64; when the distance from the reverse fault is $10 \mathrm{~m}$, the maximum vertical stress of the coal body is $18.52 \mathrm{MPa}$, and the stress concentration coefficient is 1.85. It was also found that, with the decrease of the distance between the working face and the reverse fault, the stress concentration magnitude of the coal body in front of the working face increases, and the maximum value of the vertical stress increases.

\section{Numerical Simulation of the Stress in the Reverse Fault-Affected Coal Body}

To verify the calculation accuracy of the mechanical model with respect to the coal body stress and explore the mechanisms of how the stress concentration coefficient of the mined coal body would both increase and decrease under the influence of the reverse fault, the FLAC ${ }^{3 \mathrm{D}}$ numerical simulation module was used to analyze the stress variation trend of reverse fault-affected mined coal body, using which the influences on the mined coal body stress exerted by mining the hanging wall versus the footwall, as well as by reverse fault dip angle, fault throw, etc., were discussed.

3.1. Numerical Model. This study constructed the 3D numerical simulation model based on the 1503 mining face of Xinchun Coal Mine and declared the $X$-axis along the 


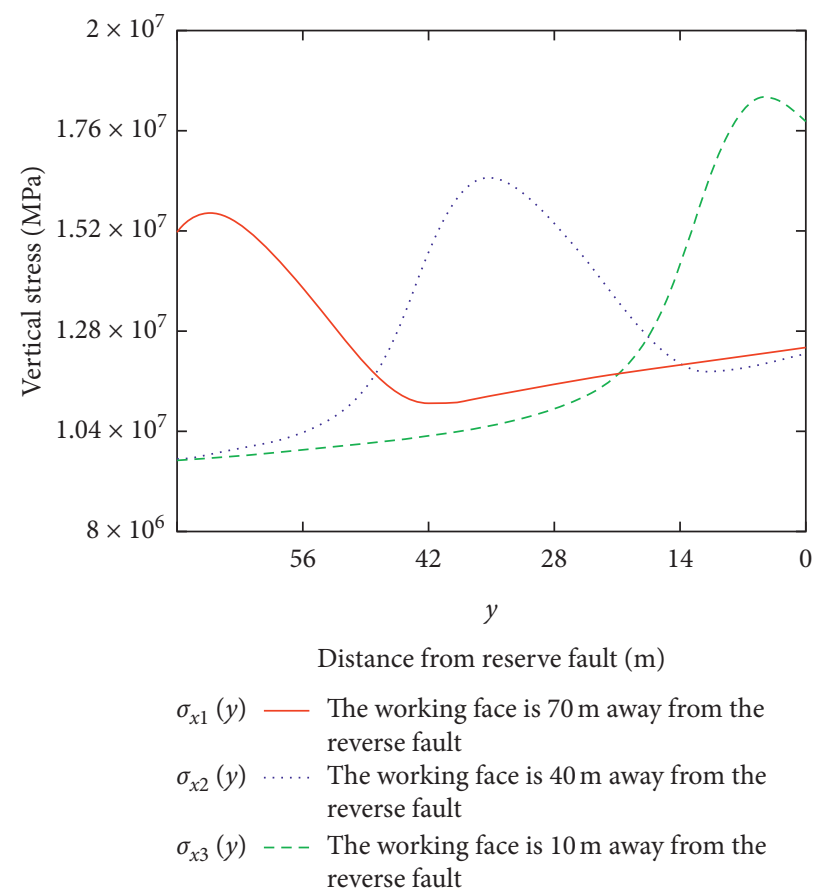

Figure 3: Vertical stress of coal body in different distance between working face and reverse fault.

direction of the coal seam, the $Y$-axis along the direction of coal seam inclination, and the $Z$-axis along the vertical direction. The reverse fault was designed with a dip angle of $60^{\circ}$ and a fault throw of $4 \mathrm{~m}$. The model measures $350 \mathrm{~m}$, $200 \mathrm{~m}$, and $103 \mathrm{~m}$ in length, dip length, and height, respectively. In the calculation, the mining process was simulated by excavation step by step, and the working face excavation was simulated by empty element. The reverse fault is simulated by adding $2 \mathrm{~m}$-long weak bands in the middle of the upper and lower walls of the model. In the simulation, the coal-rock body model was regarded as an elastoplastic body and the Mohr-Coulomb model was selected. The mechanical parameters of coal and rock mass in 1503 working face used in the simulation process are selected according to references $[18,19]$, and the mechanical parameters of coal and rock mass are as shown in Table 1. Vertical movements were limited by the $X$ and $Y$ directions of the model and the $Z$-direction of the bottom plane. The upper part is a free surface, on which a vertical load is to be applied to simulate the dead weight of the overlying strata. The vertical stress is $9.0 \mathrm{MPa}$, and stress with 1.5 times of that magnitude will be applied along the horizontal direction.

\subsection{Stress Variation of the Reverse Fault-Mined Coal Body}

3.2.1. Variation of Hanging-Wall Mining-Inflicted Stress on the Coal Body. When the working face was $70 \mathrm{~m}, 40 \mathrm{~m}$, and $10 \mathrm{~m}$ away from the reverse fault, the vertical stress distribution of coal body is shown in Figure 4 .

When the working face is $70 \mathrm{~m}$ away from the reverse fault, under the shearing action of the reverse fault, the roof of the coal seam becomes wedged, the vertical stress concentration of surrounding rock is relatively low, and the maximum vertical stress of the coal body in front of the working face is $18.2 \mathrm{MPa}$. When the working face is $40 \mathrm{~m}$ away from the reverse fault, the vertical stress concentration magnitude of the coal body in front of the working face increases, and the maximum vertical stress increases to 19.2 MPa. Lastly, when the working face is $10 \mathrm{~m}$ away from the reverse fault, the vertical stress concentration of the coal body in front of the working face further increases, and the maximum vertical stress rises to $19.8 \mathrm{MPa}$. From the statistics above, it can be concluded that, when the working face is mined toward the direction of the reverse fault, as the distance from the reverse fault decreases, the stress concentration magnitude of the coal body in front of the working face gradually increases, and the maximum of the advanced stress gradually increases.

Stress monitoring points were arranged at $65 \mathrm{~m}, 35 \mathrm{~m}$, and $5 \mathrm{~m}$ away from the reverse fault, and the variation curve of the vertical stresses at the monitoring points was obtained as the mining activity on the working face proceeds, as shown in Figure 5.

With the advancement of the working face, the vertical stresses of the coal body at the monitoring points significantly increase. When the mining face is $110 \mathrm{~m}$ away from the reverse fault, the stresses captured by the three monitoring points show little difference. The monitoring point at the $65 \mathrm{~m}$ point is closer to the working face at this instance; hence, the greater influence from the mining activities and the highest vertical stress were recorded. The $5 \mathrm{~m}$ monitoring point is farthest from the working face; thus, the influence of mining activities is relatively small and the vertical stress is the least. At $70 \mathrm{~m}$ away from the reverse fault, the maximum vertical stress read by the monitoring point at the $65 \mathrm{~m}$ point 
TABLE 1: Rock mechanics parameters of 1503 working face in Xinchun coal mine.

\begin{tabular}{|c|c|c|c|c|c|c|c|c|c|}
\hline Lithology & $\begin{array}{c}\text { Thickness } \\
(\mathrm{m})\end{array}$ & $\begin{array}{l}\text { Density } \\
\left(\mathrm{kg} \cdot \mathrm{m}^{3}\right)\end{array}$ & $\begin{array}{c}\text { Elastic } \\
\text { modulus } \\
(\mathrm{GPa})\end{array}$ & $\begin{array}{l}\text { Poisson's } \\
\text { ratio }\end{array}$ & $\begin{array}{c}\text { Bulk } \\
\text { modulus } \\
(\mathrm{GPa})\end{array}$ & $\begin{array}{c}\text { Shear } \\
\text { modulus } \\
(\mathrm{GPa})\end{array}$ & $\begin{array}{c}\text { Cohesion } \\
(\mathrm{MPa})\end{array}$ & $\begin{array}{c}\text { Tensile } \\
\text { strength } \\
(\mathrm{MPa})\end{array}$ & $\begin{array}{c}\text { Internal } \\
\text { friction angle } \\
\left({ }^{\circ}\right)\end{array}$ \\
\hline Sandstone & 49 & 2540 & 17.55 & 0.24 & 14.7 & 8.1 & 10.0 & 11.55 & 26 \\
\hline $\begin{array}{l}\text { Sandy } \\
\text { mudstone }\end{array}$ & 12 & 2600 & 15.45 & 0.27 & 10.5 & 7.1 & 1.7 & 2.30 & 30 \\
\hline Coal & 2 & 1350 & 3.53 & 0.33 & 10.5 & 6.5 & 1.2 & 0.90 & 23 \\
\hline Mudstone & 8 & 2340 & 4.92 & 0.35 & 9.8 & 7.1 & 0.5 & 1.55 & 39 \\
\hline $\begin{array}{l}\text { Silty } \\
\text { mudstone }\end{array}$ & 15 & 2530 & 7.33 & 0.31 & 10.4 & 7.3 & 0.7 & 1.65 & 38 \\
\hline Siltstone & 17 & 2580 & 10.23 & 0.31 & 13.4 & 7.6 & 1.4 & 1.85 & 37 \\
\hline Fault & 2 & 2000 & 1.10 & 0.12 & 4.1 & 1.3 & 0.4 & 0.2 & 5 \\
\hline
\end{tabular}

reaches $15.6 \mathrm{MPa}$. After that, the coal body at the monitoring point is mined and the stress returns to 0 . When the working face advances to $40 \mathrm{~m}$ away from the reverse fault, the maximum vertical stress at the $35 \mathrm{~m}$ monitoring point reaches $16.2 \mathrm{MPa}$. Lastly, when the working face is $10 \mathrm{~m}$ from the reverse fault, the maximum vertical pressure at the $5 \mathrm{~m}$ monitoring point rises to $18.4 \mathrm{MPa}$.

Compared with the results of mechanical calculation, the numerical simulation results are identical to the conclusion of mechanical analysis. The stress concentration magnitude of the coal body in front of the working face is gradually increasing, and the maximum stress value is constantly increasing. Moreover, the stress concentration magnitude of theoretical calculation is basically consistent with the results in Figure 5, which again confirms the accuracy of theoretical analysis.

3.2.2. Variation of Footwall Mining-Inflicted Stress on the Coal Body. In order to analyze the footwall mining-inflicted stress on the coal body, when the working face was $70 \mathrm{~m}$, $40 \mathrm{~m}$, and $10 \mathrm{~m}$ away from the reverse fault, the vertical stress distribution of coal body was shown in Figure 6.

During footwall face mining, the coal body stress distribution also shows a variation trend whereby the closer the coal body gets to the reverse fault, the more concentrated the coal stress becomes. When the footwall working face is $70 \mathrm{~m}$ away from the reverse fault, the maximum vertical stress in front of the working face is $17.4 \mathrm{MPa} ; 40 \mathrm{~m}$ away, the maximum vertical stress becomes $18.9 \mathrm{MPa} ; 10 \mathrm{~m}$ away, and the maximum vertical stress rises to $19.0 \mathrm{MPa}$. Comparing the stress distribution in the event of hanging wall mining, it can be concluded that footwall mining incurs weaker stress concentration.

Stress monitoring points were arranged at $65 \mathrm{~m}, 35 \mathrm{~m}$, and $5 \mathrm{~m}$ away from the reverse fault, and the variation curve of the vertical stresses at the monitoring points was obtained as the mining activity on the working face proceeds, as shown in Figure 7.

With the advancement of the working face, the stresses recorded at the monitoring points increase. When the working face is $70 \mathrm{~m}$ away from the reverse fault, the maximum vertical pressure at the $65 \mathrm{~m}$ monitoring point reaches $17.0 \mathrm{MPa}$; at $40 \mathrm{~m}$ away, the maximum vertical pressure at the $35 \mathrm{~m}$ monitoring point reaches $18.4 \mathrm{MPa}$;
$10 \mathrm{~m}$ away, and the maximum vertical pressure at the $5 \mathrm{~m}$ monitoring point becomes $18.8 \mathrm{MPa}$. This shows that the stress variation trends for both the hanging wall and footwall mining cases are equivalent and that the working face positions affect the stress concentration magnitude of the coal body.

\subsection{Influence of Reverse Fault Parameters on Stress Variation in Mined Coal Body}

3.3.1. Influence of Reverse Fault Dip Angle on Coal Body Stress. Four reverse fault mining simulation models were established. Adjustments made for the model used throughout this experimental section were as follows. The mechanical properties of the fault plane are the same, the fault throw, the rock physical and mechanical properties are the same, and only the reverse fault dip angle has been changed to $30^{\circ}, 45^{\circ}, 60^{\circ}$, and $75^{\circ}$, respectively. The stress distribution characteristics of the mined coal body are as shown in Figures 8-10.

When the working face is $70 \mathrm{~m}$ and $40 \mathrm{~m}$ away from the reverse fault, the larger is the reverse fault dip angle and the smaller is the maximum advanced stress of the coal body. This is caused by the varying reverse fault dip angles, which diversify the volume of the resulting trapezoidal coal pillars between the working face and the reverse fault. Analogously, the smaller the dip angle, the larger the coal volume above the coal pillar and the higher the load. Moreover, the presence of a reverse fault structure has also diminished the effectiveness of stress transfer across the mined coal bodies, increasing the gravity load on the coal pillars as well as the stress concentration.

When the working face is $10 \mathrm{~m}$ away from the reverse fault, the stress on the coal body in front of the working face reaches its maximum when the dip angle of the reverse fault is $45^{\circ}$. Compared with the stress concentration area in front of the working face in Figure 10, part of the coal body stress concentration area does not reach its maximum at the $30^{\circ}$ dip angle reverse fault, whereas the maximum is reached at other dip angles. This suggests that only part of the coal body can still bear the load effectively in the stress concentration area at the $30^{\circ}$ dip angle, whereas the remaining coal body part has failed and completely lost its load-bearing capacity, hence resulting in the reduction in stress concentration 


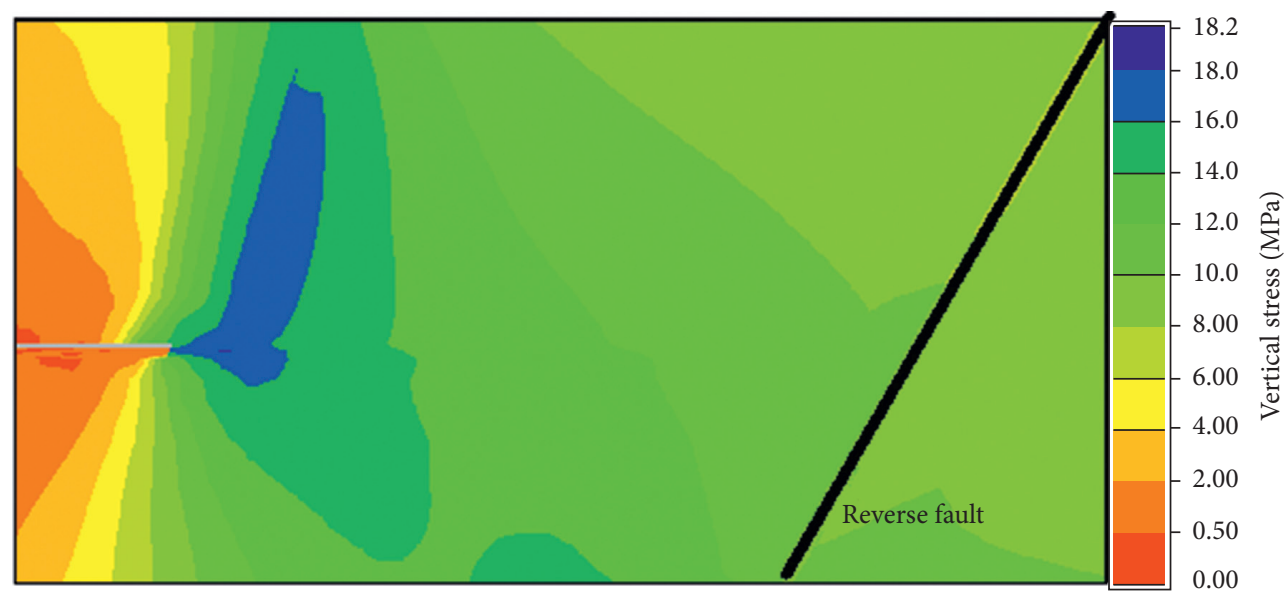

(a)

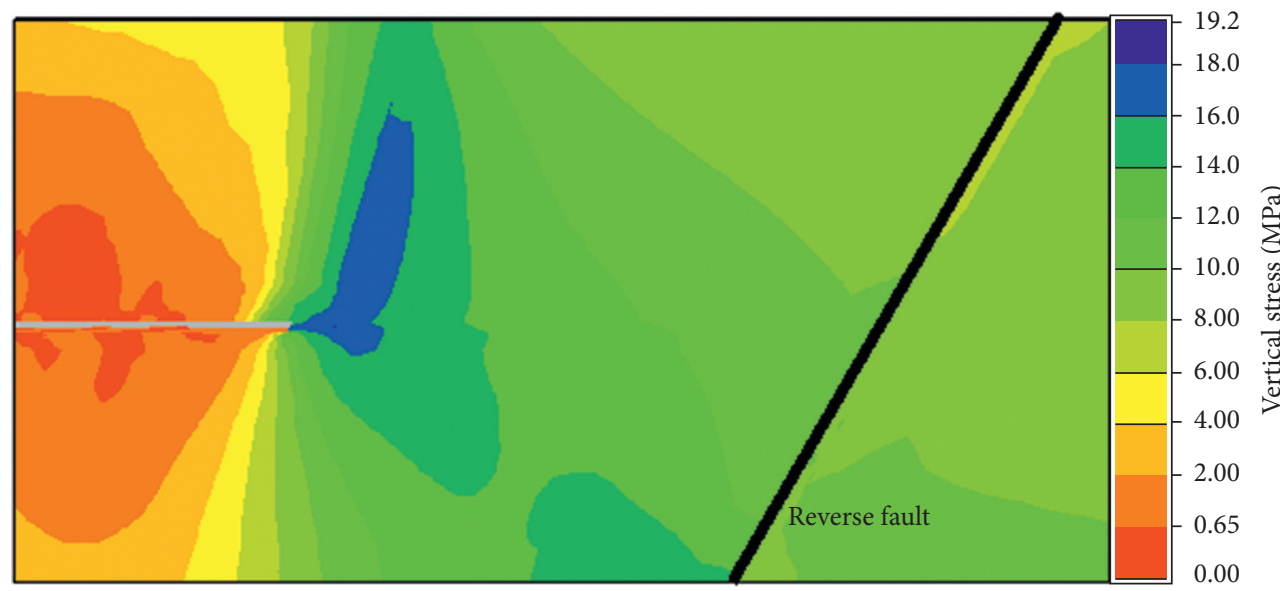

(b)

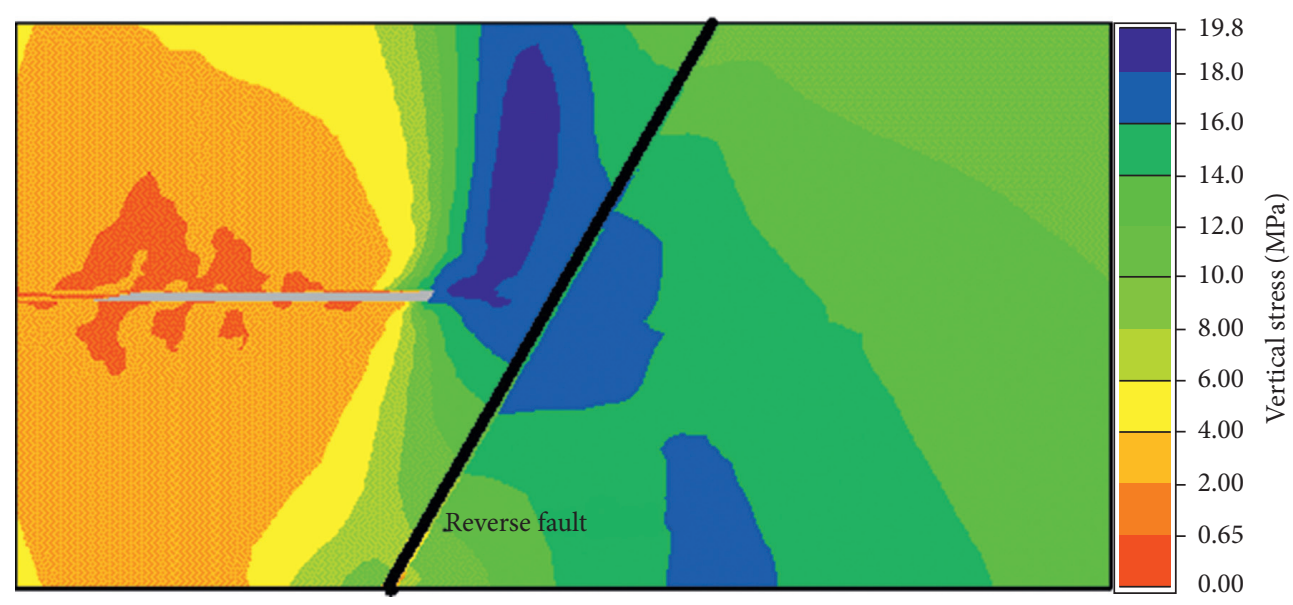

(c)

Figure 4: Variation of hanging-wall mining-inflicted stress on the coal body under different distance between working face and reverse fault. (a) The working face is $70 \mathrm{~m}$ away from the reverse fault. (b) The working face is $40 \mathrm{~m}$ away from the reverse fault. (c) The working face is $10 \mathrm{~m}$ away from the reverse fault.

magnitude. This conclusion further verifies that obtained in the theoretical analysis, which also claims the reduction in stress concentration.

Stress monitoring points were arranged at $65 \mathrm{~m}, 35 \mathrm{~m}$, and $5 \mathrm{~m}$ away from the reverse fault, and the variation curve of the vertical stresses at the monitoring points was obtained as the mining activity on the working face proceeds, as shown in Figure 11.

At $45^{\circ}, 60^{\circ}$, and $75^{\circ}$ dip angles, the stress concentration magnitudes of the coal body in front of the working face 


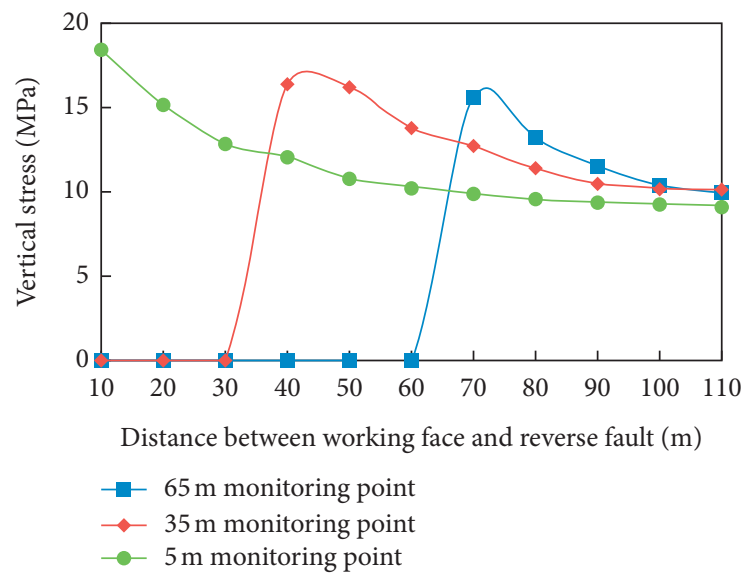

Figure 5: Variation curve of the vertical stresses at the monitoring points in hanging-wall mining.

gradually increase, whereas at $30^{\circ}$ dip angle, the stress concentration magnitude of the coal body in front of the working face gradually increases first before decreasing once the distance from the reverse fault reaches $10 \mathrm{~m}$. It is also worthy to note that the change in reverse fault dip angle mainly affects the stress concentration magnitude of the coal body in front of the working face, and not the stress variation trend.

When the working face is far away from the monitoring point, the vertical stress is the initial stress, and when the working face is $35 \mathrm{~m}$ away from the monitoring point, the vertical stress begins to rise obviously. By comparing both the two stresses, it can be seen that the value of the stress where the increase is the most significant is 1.02-1.39 times that of the initial stress, as shown in Table 2.

\subsubsection{Influence of Reverse Fault Throw on Coal Body Stress.} Four reverse fault mining simulation models were established. Adjustments made for the model used throughout this experimental section were as follows. The mechanical properties of the fault plane are the same, the fault dip angle, the rock physical and mechanical properties are the same, and only the reverse fault throw has been changed to $4 \mathrm{~m}$, $10 \mathrm{~m}, 15 \mathrm{~m}$, and $20 \mathrm{~m}$, respectively. The stress distribution characteristics of the mined coal body are as shown in Figures 12-14.

When the working face is $70 \mathrm{~m}$ away from the reverse fault, the maximum stress of the coal body in front of the working face is between 18.2 and $18.5 \mathrm{MPa}$; at $40 \mathrm{~m}$ away, the maximum stress is $19.2-20.4 \mathrm{MPa}$; at $10 \mathrm{~m}$ away, and the maximum stress is $19.8-20.7 \mathrm{MPa}$. The coal body stress reaches its minimum when the throw is $4 \mathrm{~m}$ and is at its maximum when the throw is $20 \mathrm{~m}$. This shows that the coal body stress increases with the fault throw.

Stress monitoring points were arranged at $65 \mathrm{~m}, 35 \mathrm{~m}$, and $5 \mathrm{~m}$ away from the reverse fault, and the variation curves of vertical stresses at the monitoring points were obtained as the mining activity on the working face proceeds, as shown in Figure 15.

When the reverse fault throws are $4 \mathrm{~m}, 10 \mathrm{~m}, 15 \mathrm{~m}$, and $20 \mathrm{~m}$, the maximum vertical stress of the coal body in front of the working face basically shows a trend of gradual increase. The change of reverse fault throw mainly affects the stress concentration degree of the coal body in front of the working face.

When the working face is far away from the monitoring point, the vertical stress is the initial stress, and when the working face is $35 \mathrm{~m}$ away from the monitoring point, the vertical stress begins to rise obviously. By comparing the two stresses, it can be seen that the value of the stress where the increase is the most significant is 1.04-1.31 times that of the initial stress, as shown in Table 3.

\section{Field Test of the Reverse Fault-Affected Coal Body Stress}

To verify the accuracy of the theoretical analysis and numerical simulation, a field test was carried out in the 1503 working face of Xinchun Coal Mine, where intrinsically safe GZY25 borehole stress sensors were used to monitor the coal body stress in front of the working face to analyze the stress variation trend of the mined coal body. GZY 25 borehole stress sensors were mainly used for monitoring the stress change of coal and rock mass, which was composed of sensor, transmitter, and junction box. At $5 \mathrm{~m}, 35 \mathrm{~m}$, and $65 \mathrm{~m}$ from the reverse fault of 1503 transport lane, the layout of measuring points was shown in Figure 2, $\Phi 42 \mathrm{~mm}$ stress test boreholes with $10 \mathrm{~m}$ depth were drilled, and the stress sensors were pushed inward using the given conveyor rod accessory. The variation of borehole stress with the advancement of the working face is as shown in Figure 16.

It can be seen that the stress variation trend of the three monitoring points is the same and that the coal stress gradually increases with the decrease of the distance from the working face. When the distance separating the working face and the monitoring point is $35 \mathrm{~m}$, the stress starts to increase obviously. The stress change reaches its maximum when the separation lessens to $5 \mathrm{~m}$. The stress change at the $5 \mathrm{~m}$ monitoring point is the largest, while the stress change at the $65 \mathrm{~m}$ monitoring point is the smallest, indicating that the closer is the distance to the reverse fault, the higher is the 


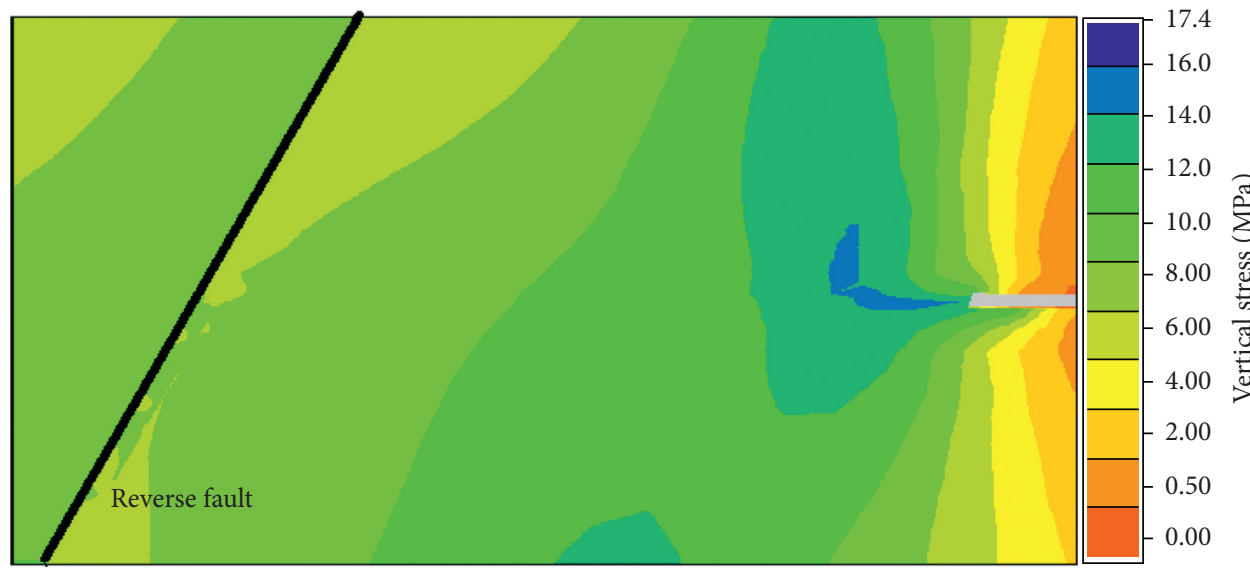

(a)

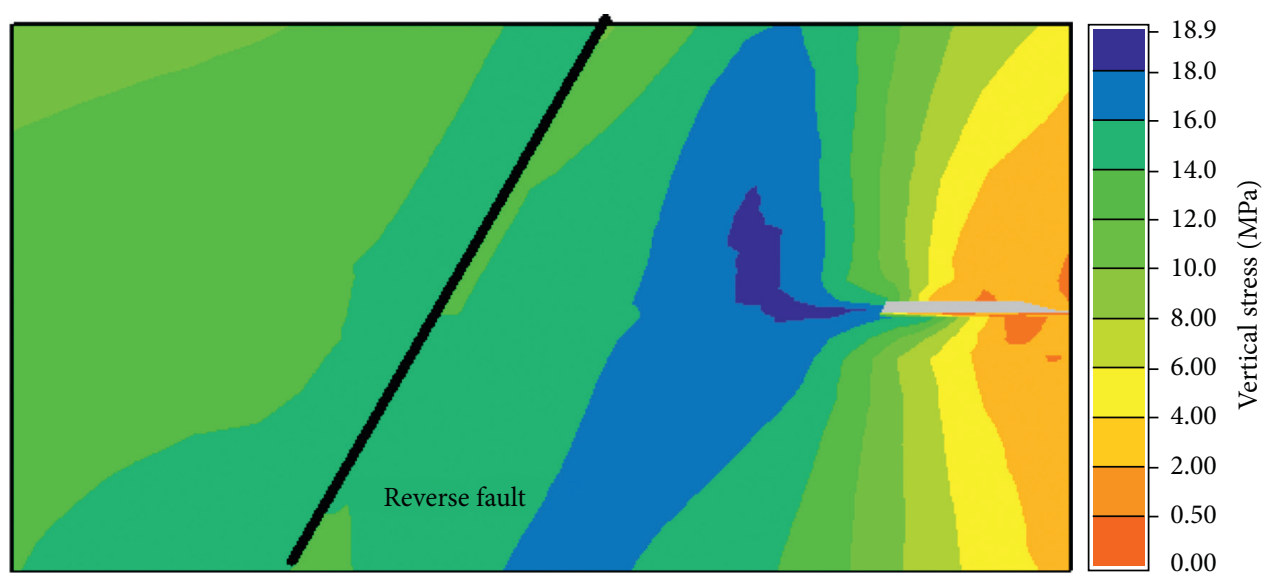

(b)

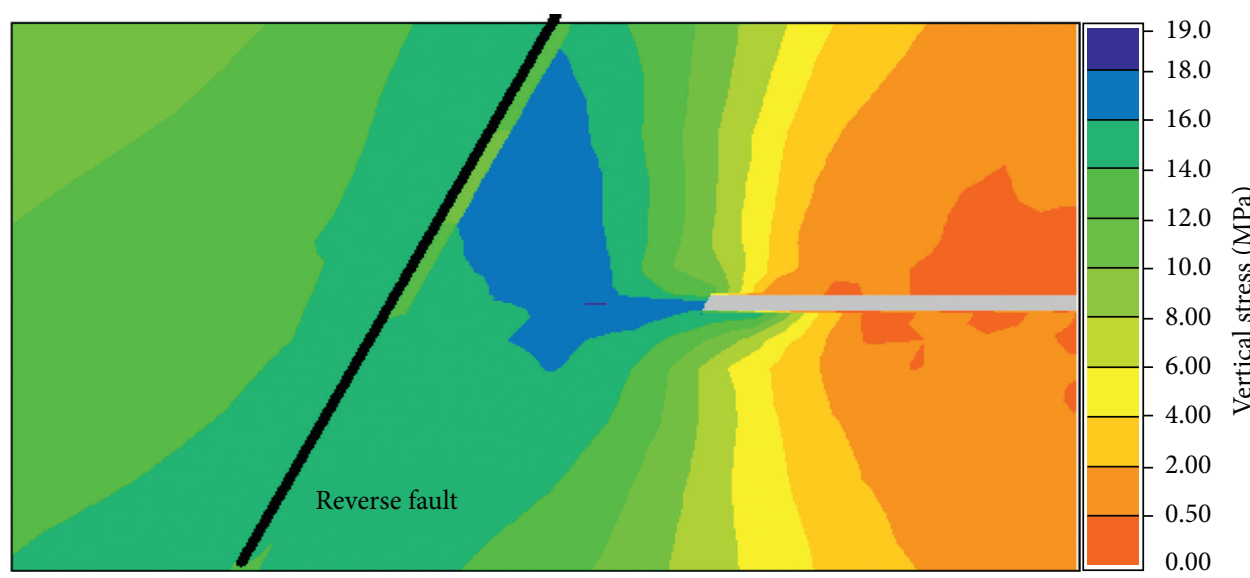

(c)

FIGURE 6: Variation of footwall mining-inflicted stress on the coal body under different distance between working face and reverse fault. (a) The working face is $70 \mathrm{~m}$ away from the reverse fault. (b) The working face is $40 \mathrm{~m}$ away from the reverse fault. (c) The working face is $10 \mathrm{~m}$ away from the reverse fault.

stress concentration magnitude of coal body in front of the working face. This finding conforms with the previously acquired variation trend, whereby the stress concentration magnitude of reverse fault-affected mined coal body gradually increases and is consistent with the conclusions reached in the theoretical analysis and numerical simulation.
Another coal body stress monitoring was also carried out in the F2 reverse fault area of the 1301 working face of ZuoQiuka Coal Mine in Guizhou Province. The dip angle of the $\mathrm{F} 2$ reverse fault was $32^{\circ}$ and the fault distance was $6.1 \mathrm{~m}$. The variation of borehole stress with the advancement of working face is as shown in Figure 17. 


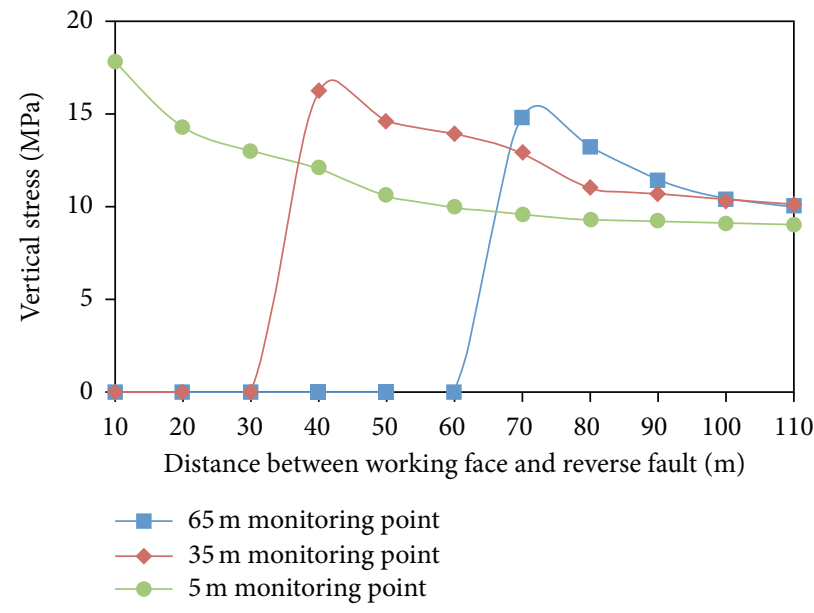

Figure 7: Variation curve of the vertical stresses at the monitoring points in footwall mining.

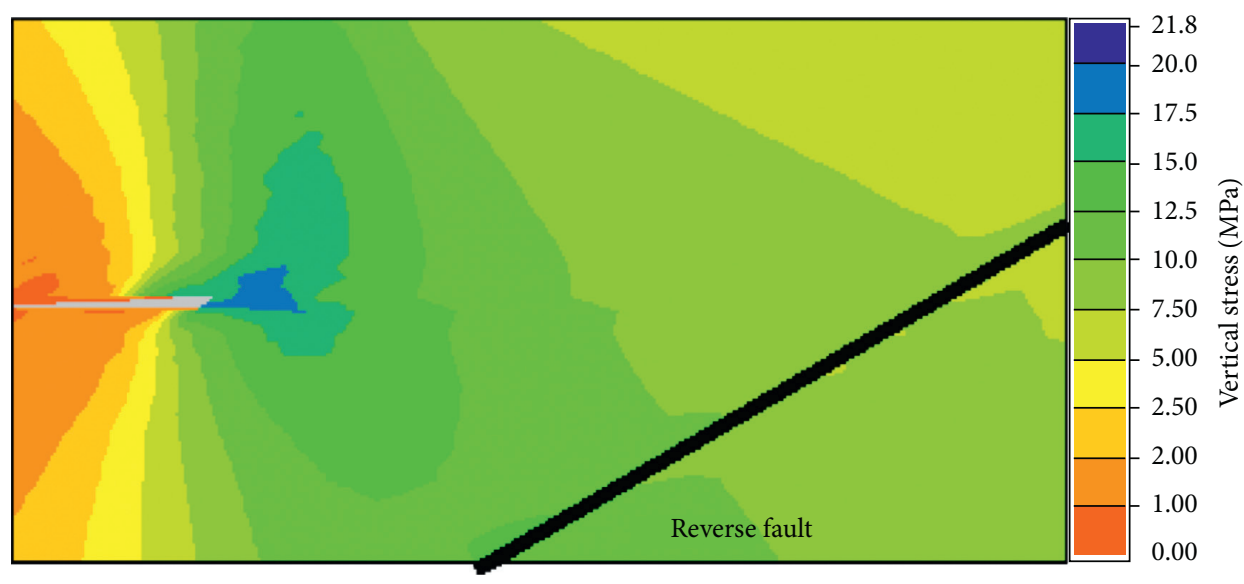

(a)

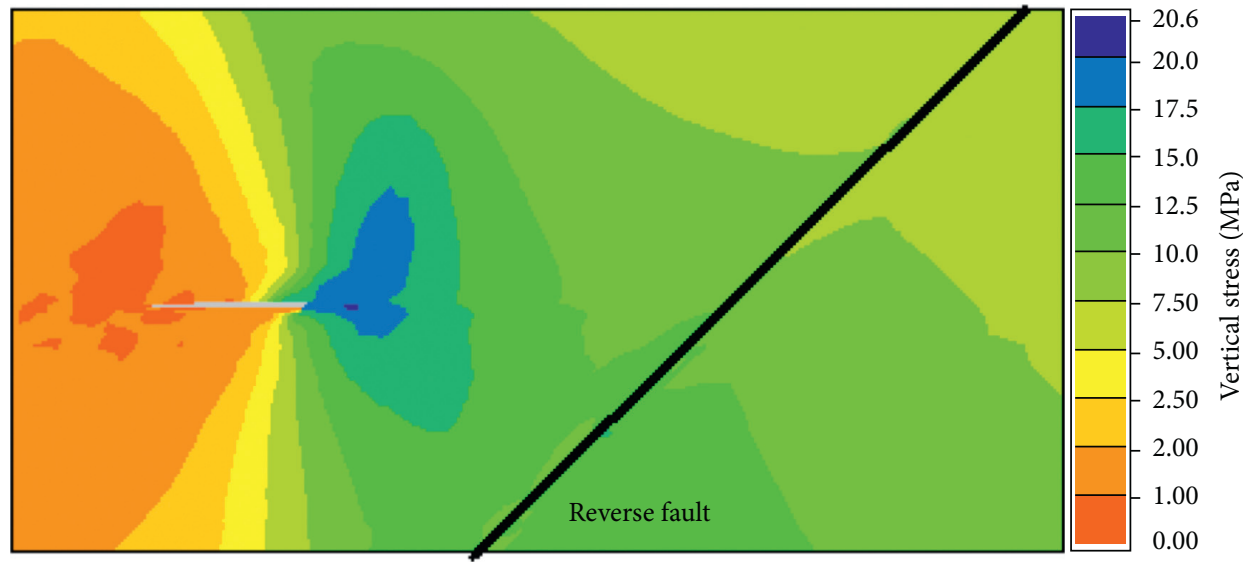

(b)

FIgURE 8: Continued. 


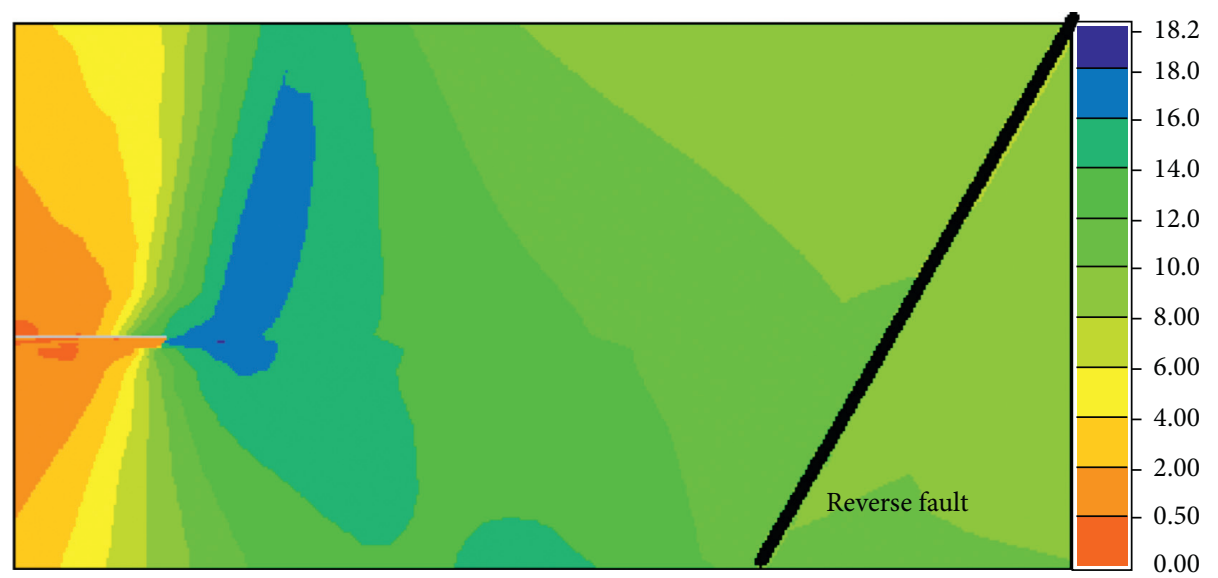

(c)

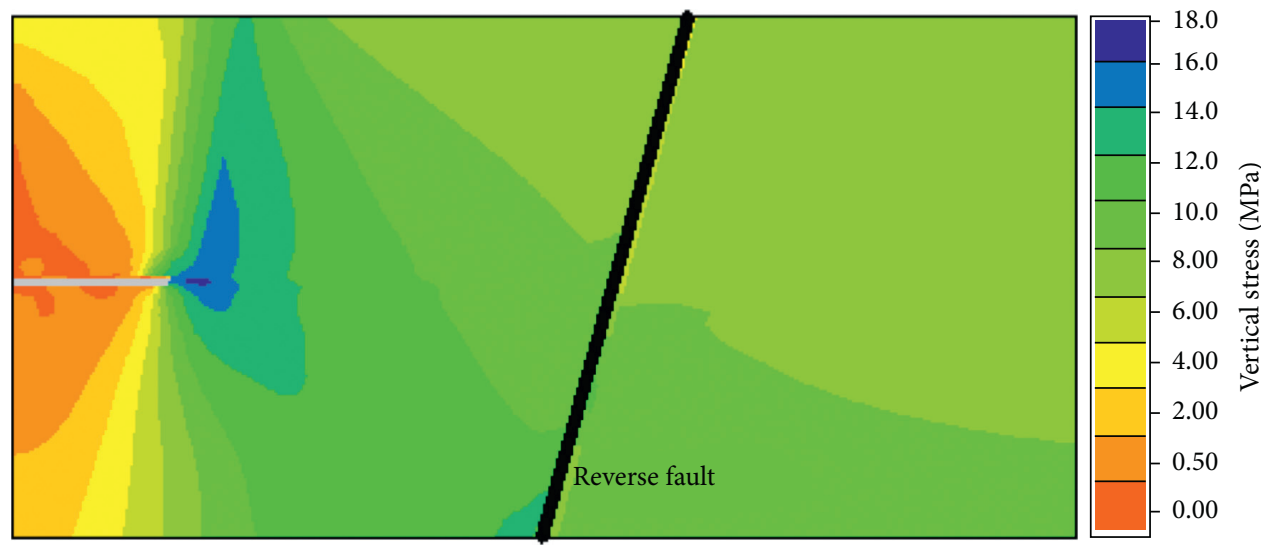

(d)

Figure 8: Stress distribution when the distance between working face and reverse fault is $70 \mathrm{~m}$ with different dip angles. (a) The dip angle of reverse fault is $30^{\circ}$. (b) The dip angle of reverse fault is $45^{\circ}$. (c) The dip angle of reverse fault is $60^{\circ}$. (d) The dip angle of reverse fault is $75^{\circ}$.

TABLE 2: Ratio of stress to initial stress when hanging wall working face is $35 \mathrm{~m}$ away from monitoring point.

\begin{tabular}{lcccc}
\hline $\begin{array}{l}\text { Location of monitoring } \\
\text { points }\end{array}$ & $\begin{array}{c}\text { Stress ratio of } 30^{\circ} \text { reverse } \\
\text { fault }\end{array}$ & $\begin{array}{c}\text { Stress ratio of } 45^{\circ} \text { reverse } \\
\text { fault }\end{array}$ & $\begin{array}{c}\text { Stress ratio of } 60^{\circ} \text { reverse } \\
\text { fault }\end{array}$ & $\begin{array}{c}\text { Stress ratio of } 75^{\circ} \text { reverse } \\
\text { fault }\end{array}$ \\
\hline $65 \mathrm{~m}$ monitoring-point & 1.44 & 1.14 & 1.04 & 1.02 \\
$35 \mathrm{~m}$ monitoring-point & 1.32 & 1.33 & 1.27 & 1.23 \\
$5 \mathrm{~m}$ monitoring-point & 1.39 & 1.23 & 1.21 & 1.15 \\
\hline
\end{tabular}

TABLE 3: Ratio of stress to initial stress when working face is $35 \mathrm{~m}$ away from monitoring point.

\begin{tabular}{lcccc}
\hline $\begin{array}{l}\text { Location of monitoring } \\
\text { points }\end{array}$ & $\begin{array}{c}\text { Stress ratio of } 4 \mathrm{~m} \text { fault } \\
\text { throw }\end{array}$ & $\begin{array}{c}\text { Stress ratio of } 10 \mathrm{~m} \text { fault } \\
\text { throw }\end{array}$ & $\begin{array}{c}\text { Stress ratio of } 15 \mathrm{~m} \text { fault } \\
\text { throw }\end{array}$ & $\begin{array}{c}\text { Stress ratio of } 20 \mathrm{~m} \text { fault } \\
\text { throw }\end{array}$ \\
\hline $65 \mathrm{~m}$ monitoring-point & 1.04 & 1.05 & 1.04 & 1.03 \\
$35 \mathrm{~m}$ monitoring-point & 1.27 & 1.20 & 1.29 & 1.31 \\
$5 \mathrm{~m}$ monitoring-point & 1.21 & 1.20 & 1.21 & 1.22 \\
\hline
\end{tabular}

It can be seen that as the distance from the working face decreases, the stresses at the three monitoring points gradually increase. However, the maximum vertical stress concentration at the monitoring point located $35 \mathrm{~m}$ away from the reverse fault is higher than that at the monitoring point located $5 \mathrm{~m}$ away, indicating that the coal body at the $5 \mathrm{~m}$ monitoring point failed and lost its load-bearing capacity, so the stress concentration magnitude decreases. It has also been verified that the stress concentration magnitude of the coal body decreases. Also, when the working face is $40 \mathrm{~m}$ away from the reverse fault, the vertical stress of the $5 \mathrm{~m}$ monitoring point increases obviously; when the $35 \mathrm{~m}$ monitoring point is $60 \mathrm{~m}$ away from the reverse fault, the vertical stress is significantly increased, indicating that when 


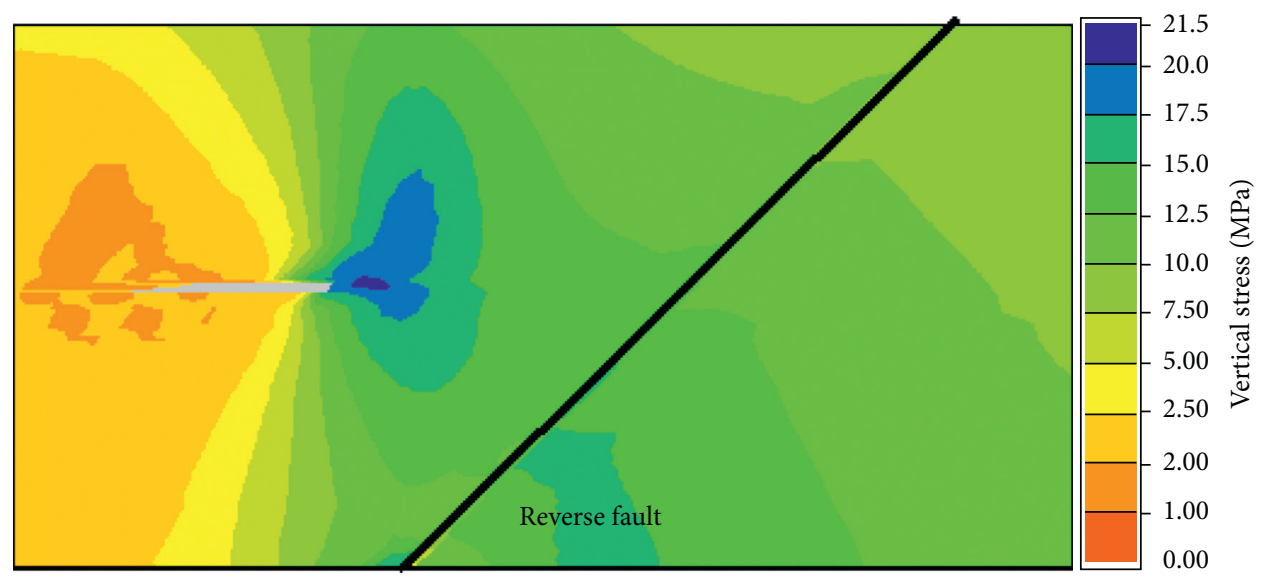

(a)

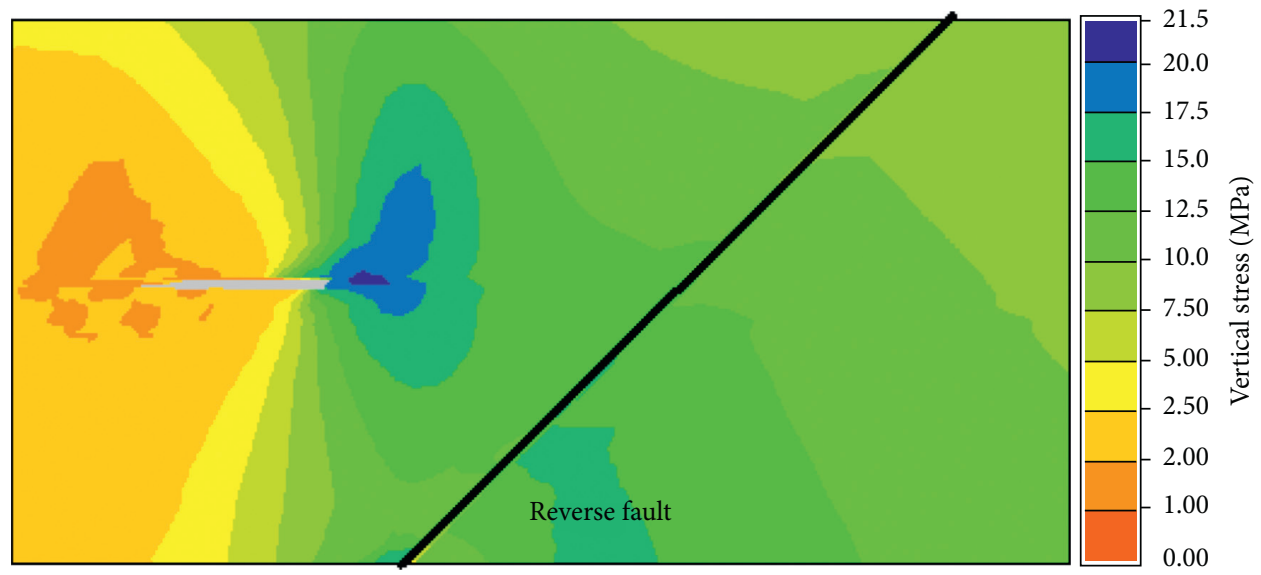

(b)

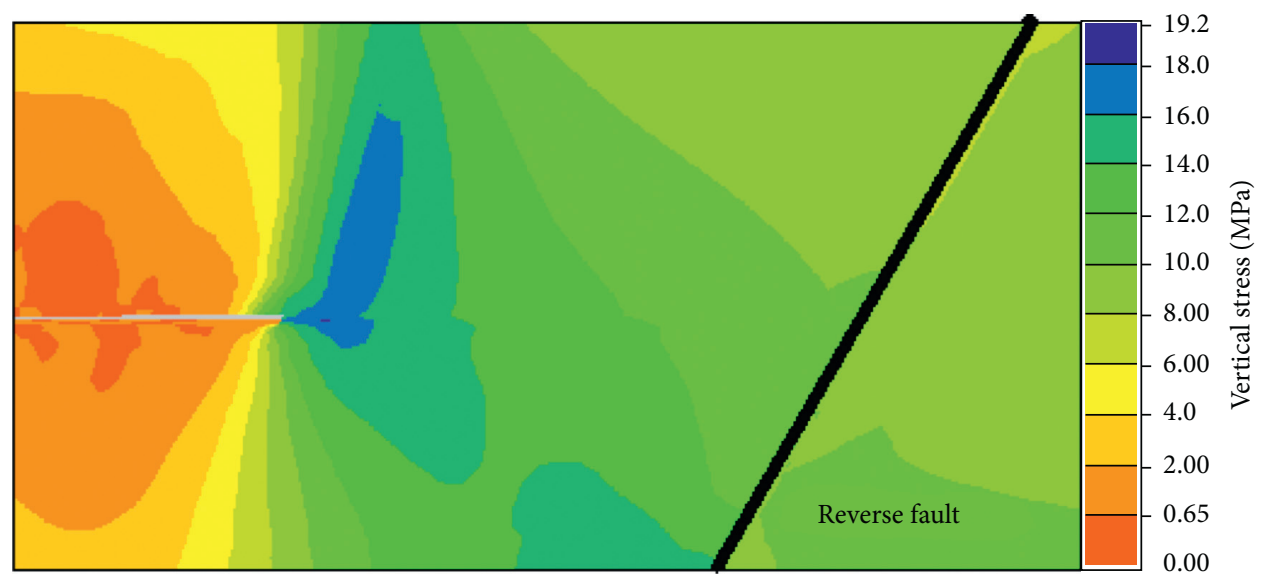

(c)

Figure 9: Continued. 

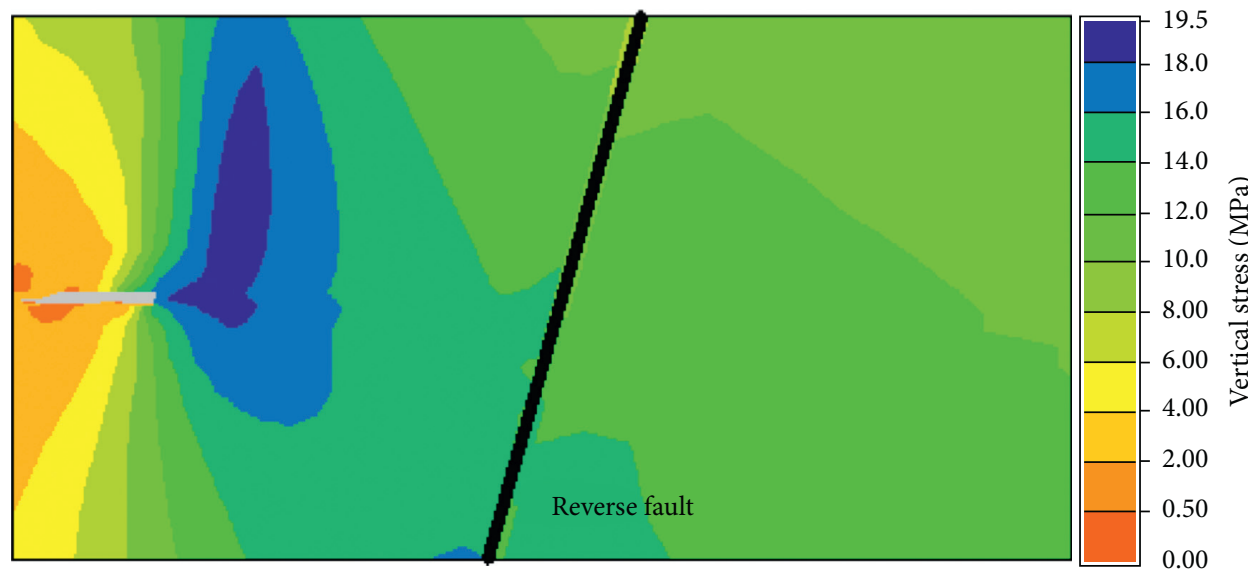

(d)

Figure 9: Stress distribution when the distance between working face and reverse fault is $40 \mathrm{~m}$ with different dip angles. (a) The dip angle of reverse fault is $30^{\circ}$. (b) The dip angle of reverse fault is $45^{\circ}$. (c) The dip angle of reverse fault is $60^{\circ}$. (d) The dip angle of reverse fault is $75^{\circ}$.

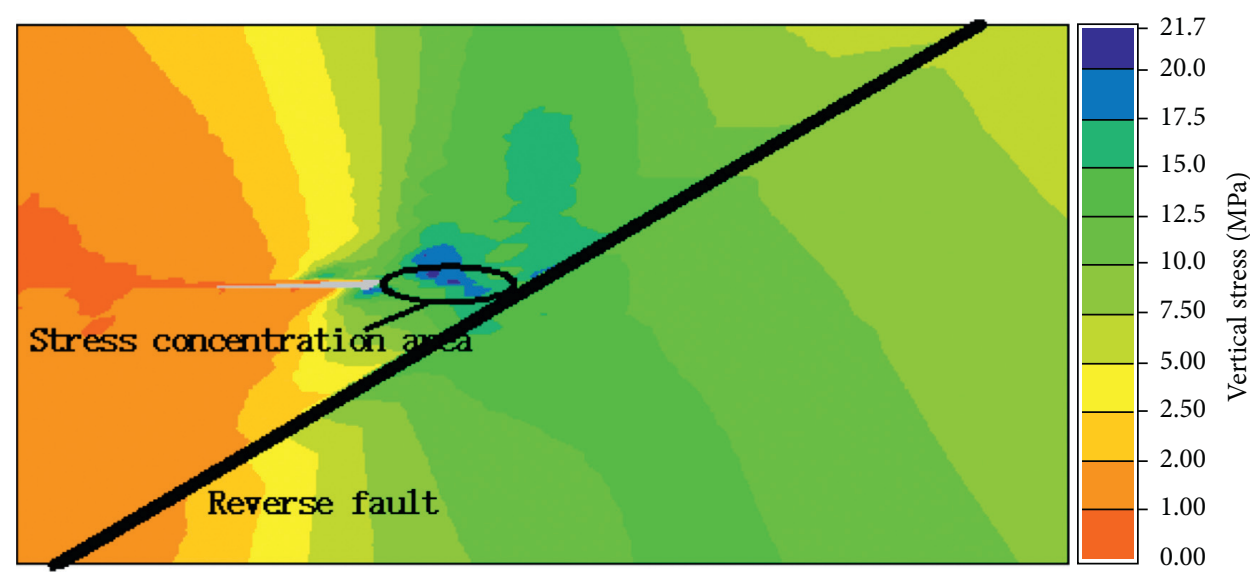

(a)

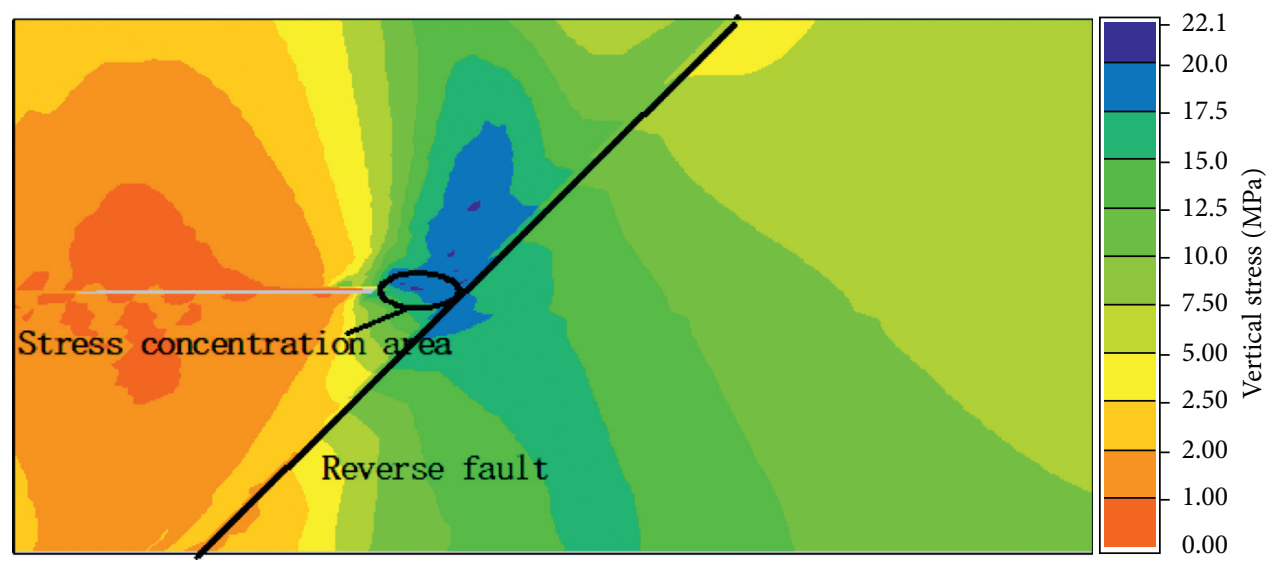

(b)

Figure 10: Continued. 


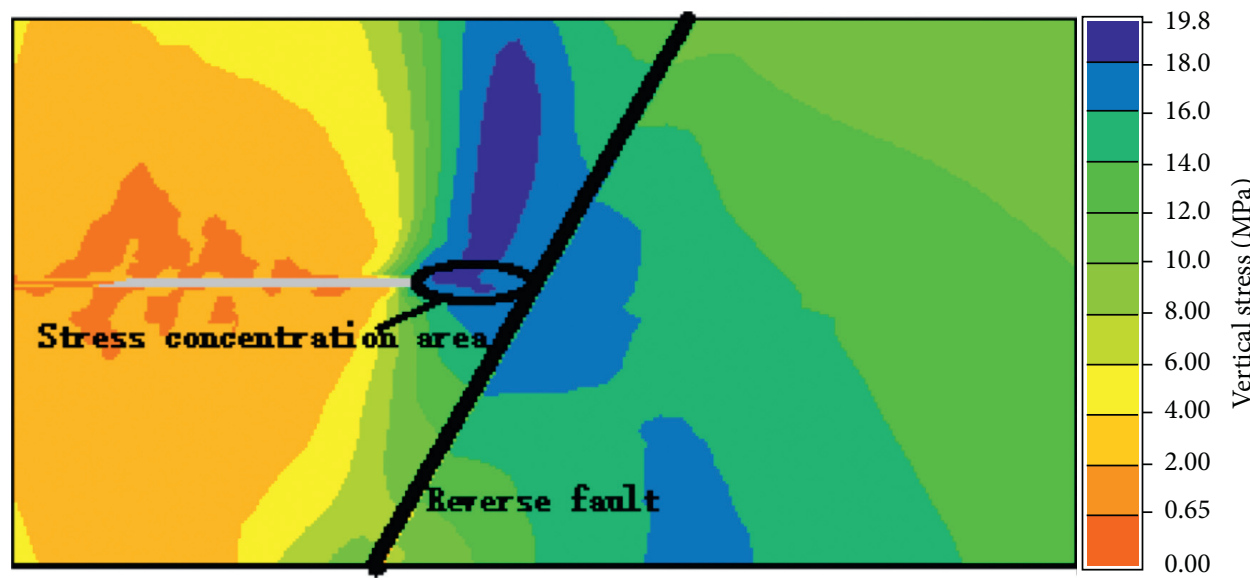

(c)

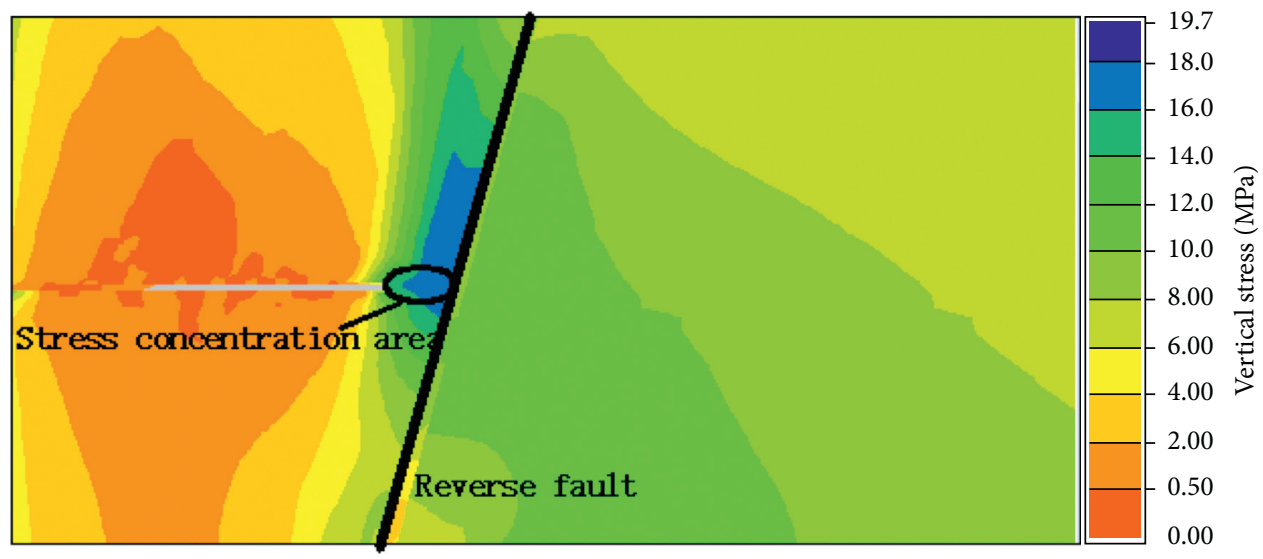

(d)

FIGURE 10: Stress distribution when the distance between working face and reverse fault is $10 \mathrm{~m}$ with different dip angles. (a) The dip angle of reverse fault is $30^{\circ}$. (b) The dip angle of reverse fault is $45^{\circ}$. (c) The dip angle of reverse fault is $60^{\circ}$. (d) The dip angle of reverse fault is $75^{\circ}$.

the working face is at a certain distance from the monitoring point, the mining-induced vertical stress on the coal body is significantly increased. This distance is related to several factors, such as mining speed, mining height, and reverse fault parameters.

\section{Stress Variation Trend of Reverse Fault- Affected Mined Coal Body}

Under the influence of mining, the coal body in the reverse fault region experienced an ongoing increase in vertical stress and an ongoing decrease in horizontal stress, until the coal body reached the point of structural failure. In the initial condition, without the influence of mining, the coal body was in the original rock tectonic stress state. With the approaching of the working face, the vertical stress of the coal body begins to rise and gradually reaches the peak pressure, before entering the pressure relief state when the coal body experiences failure, and the vertical stress decreases to the residual stress. On the other hand, when the horizontal dip stress of the coal body in front of working face is greater than that of original rock, under the influence of the inclined inlet and return air lanes of the working face, the horizontal inclined stress gradually decreases, there is no stress concentration, and the horizontal stress decreases linearly in the mining [20]. Factors such as hanging wall and footwall mining, reverse fault dip angle, and throw mainly affect the stress concentration magnitude of coal body, not the stress variation trend on the coal body.

Therefore, based on the theoretical analysis, numerical simulation, and field testing, it can be inferred that when the reach of the mining influence coincides with the test point, the vertical stress at the test point will begin to increase, and then with the further decrease in the separation between the working face and the test point, the vertical stress begins to increase significantly. At this point, the vertical stress of the coal body can be generalized as $(1.02-1.39) \gamma \cdot H$. Finally, once the test point falls on the stress concentration area in front of the working face, the vertical stress will reach its maximum at $K \cdot \gamma \cdot H$. The horizontal stress then gradually decreases [20], and the variation of coal body stress progresses as shown in Figure 18.

Under the influence of reverse fault, the value of stress concentration coefficient $K$ of the mined coal body is related to the distance $L$ from the test point to the reverse fault, which mainly includes the following two situations: 


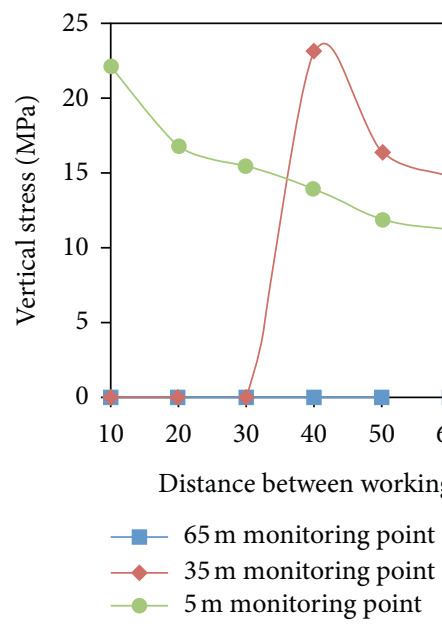

(a)

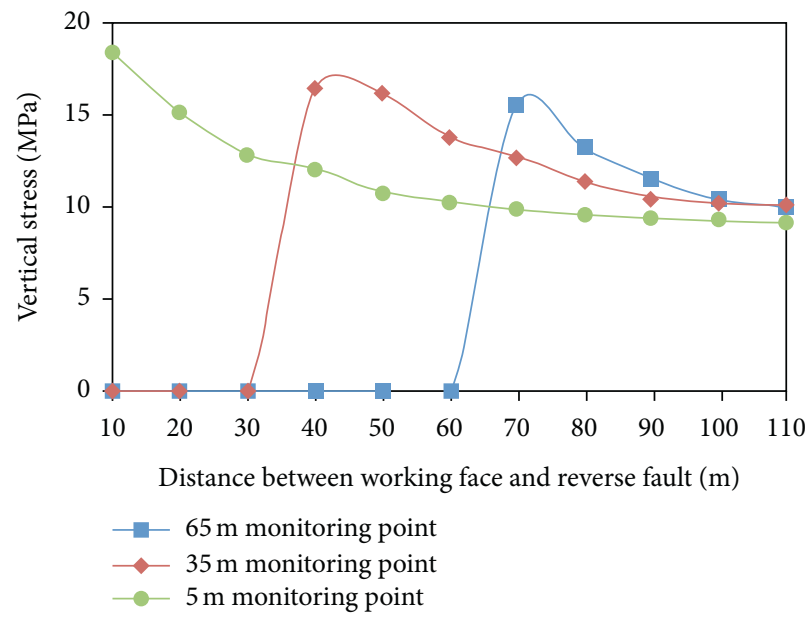

(c)

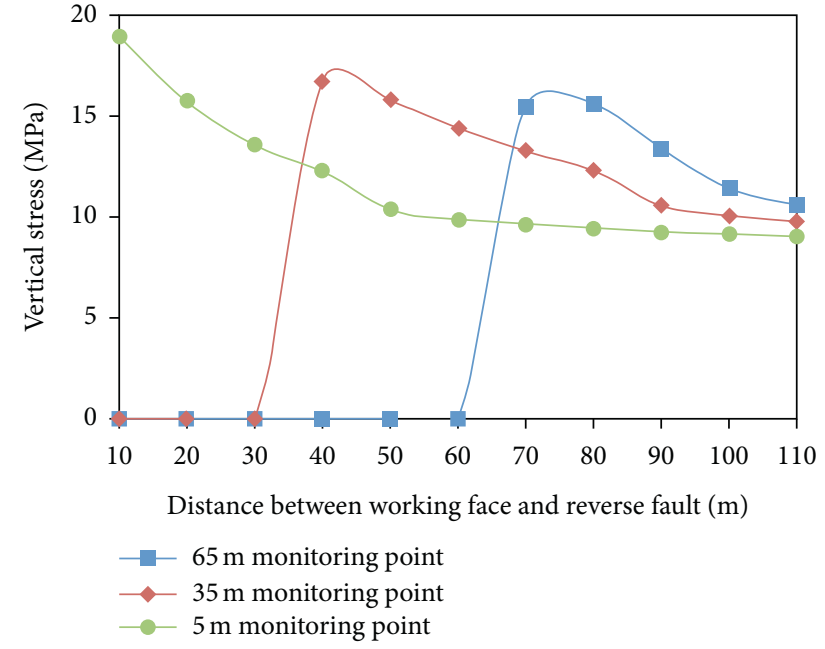

(b)

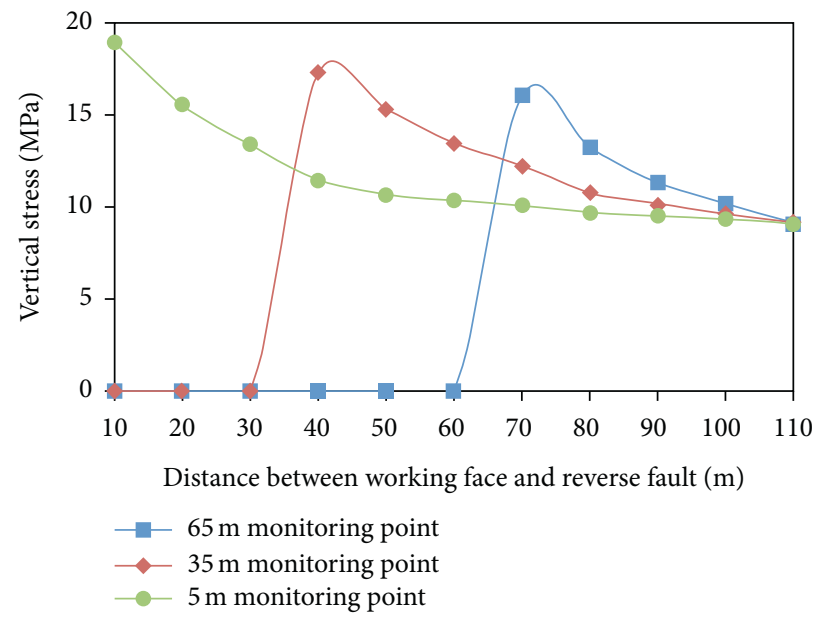

(d)

Figure 11: Variation curve of the vertical stresses at the monitoring points with different dip angles. (a) The dip angle of reverse fault is $30^{\circ}$. (b) The dip angle of reverse fault is $45^{\circ}$. (c) The dip angle of reverse fault is $60^{\circ}$. (d) The dip angle of reverse fault is $75^{\circ}$.

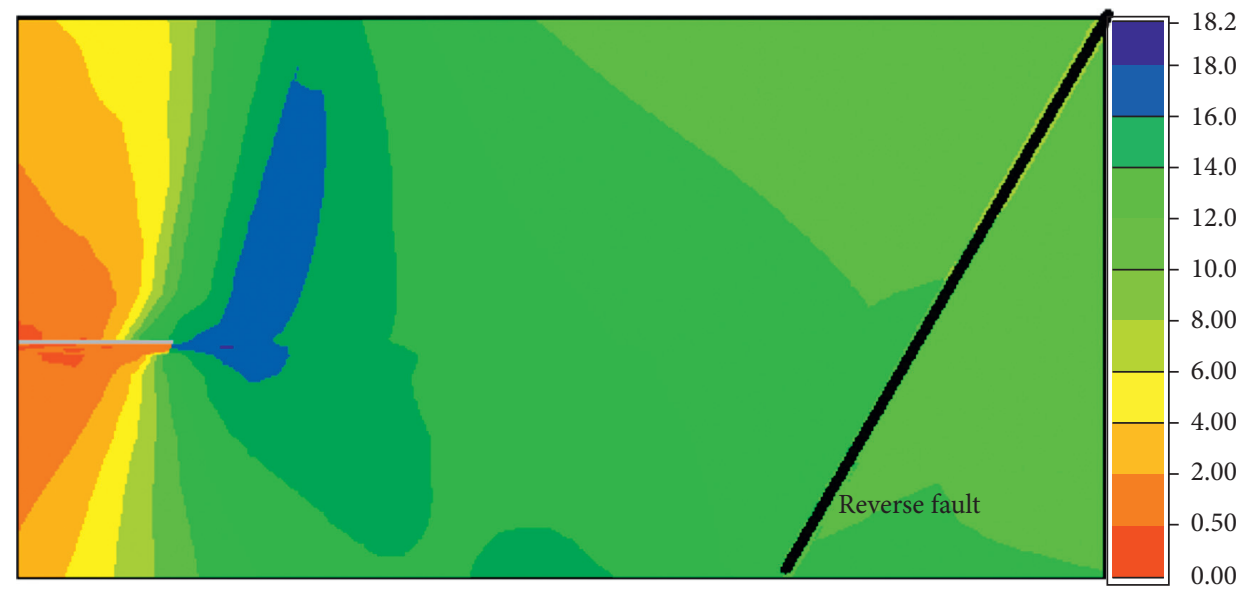

(a)

FIgURE 12: Continued. 


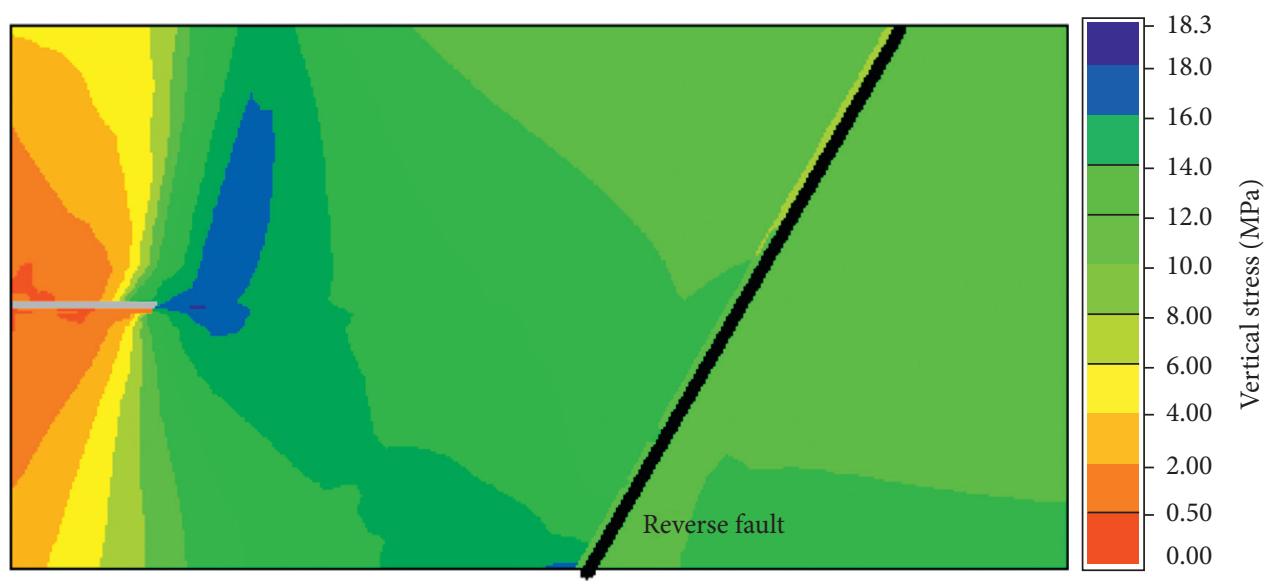

(b)

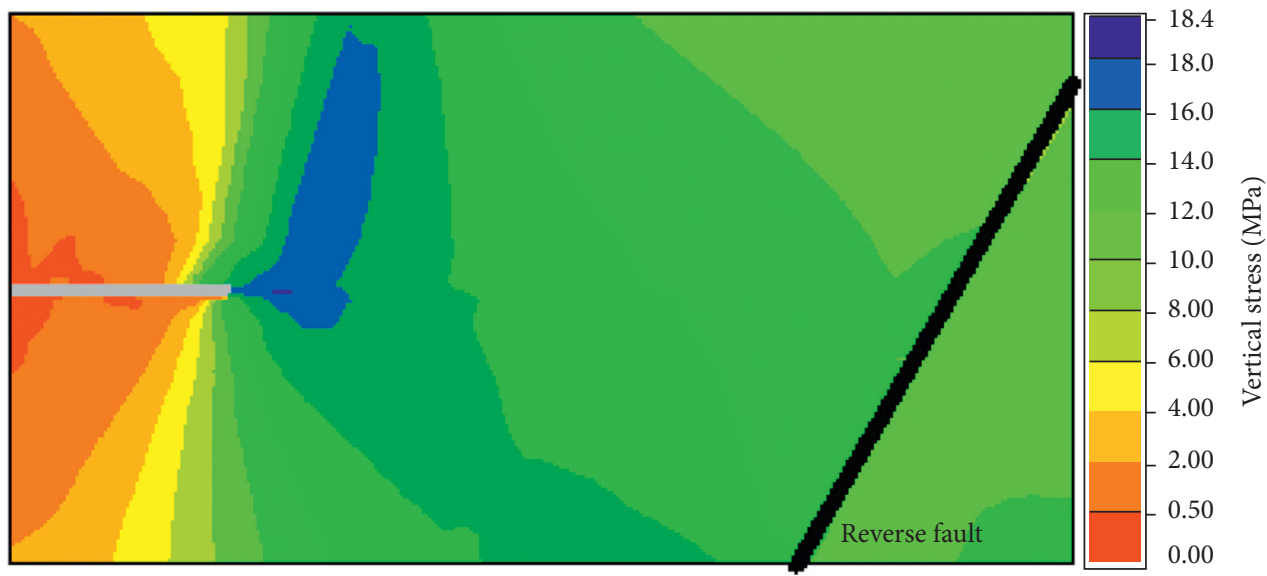

(c)

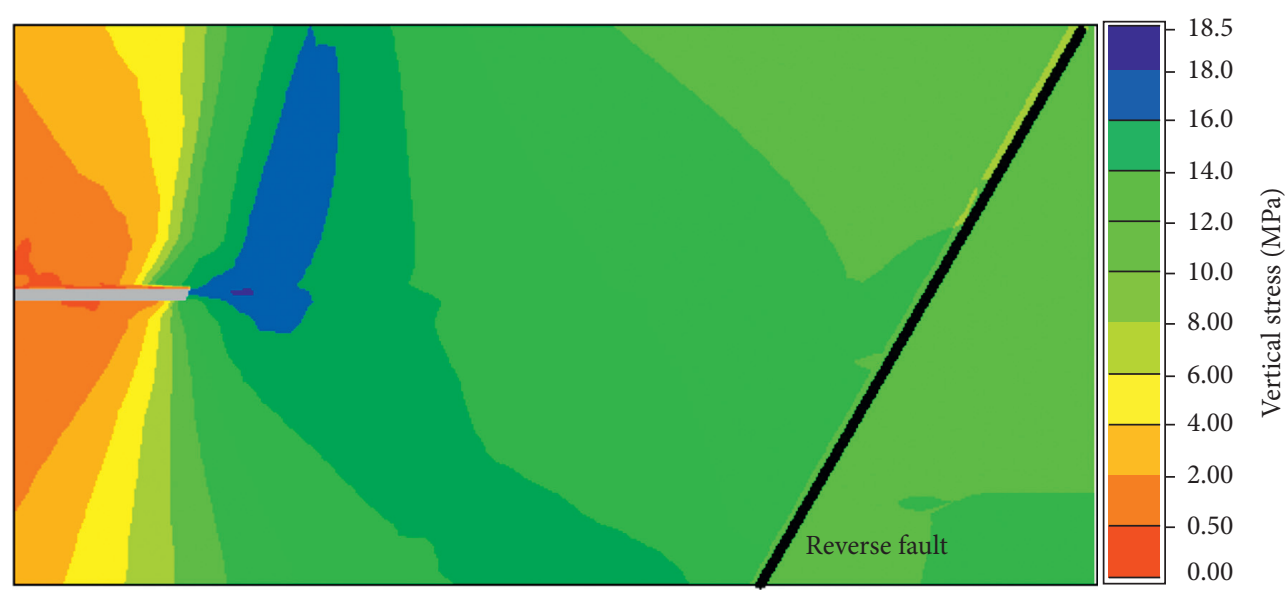

(d)

FIgURE 12: Stress distribution when the distance between working face and reverse fault is $70 \mathrm{~m}$ with different fault throw. (a) The throw of reverse fault is $4 \mathrm{~m}$. (b) The throw of reverse fault is $10 \mathrm{~m}$. (c) The throw of reverse fault is $15 \mathrm{~m}$. (d) The throw of reverse fault is $20 \mathrm{~m}$.

(1) When the working face is mined along the direction facing the reverse fault, with the decrease of the distance $L$ from the reverse fault, if the coal-bearing capacity does not exceed its strength, the coal stress in front of the working face and hence the stress concentration coefficient $K$ will increase gradually.
(2) When the working face is mined along the direction facing the reverse fault, with the decrease of the distance $L$ from the reverse fault, the stress concentration magnitude of the mined coal body increases gradually at first, before decreasing, which occurs when the bearing capacity of the coal body 


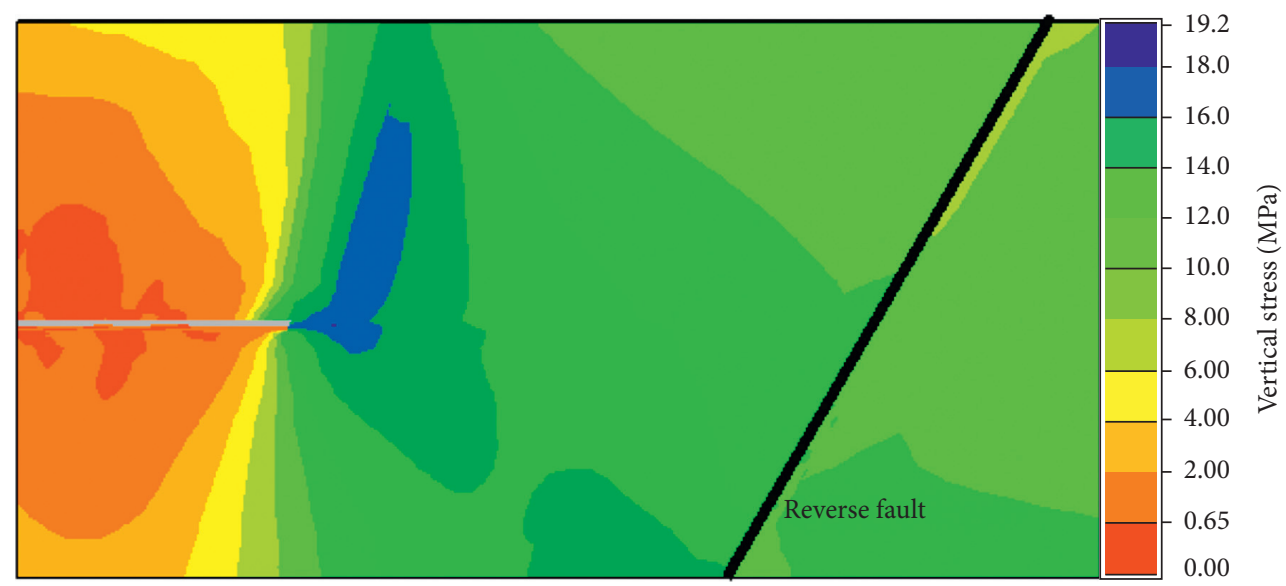

(a)

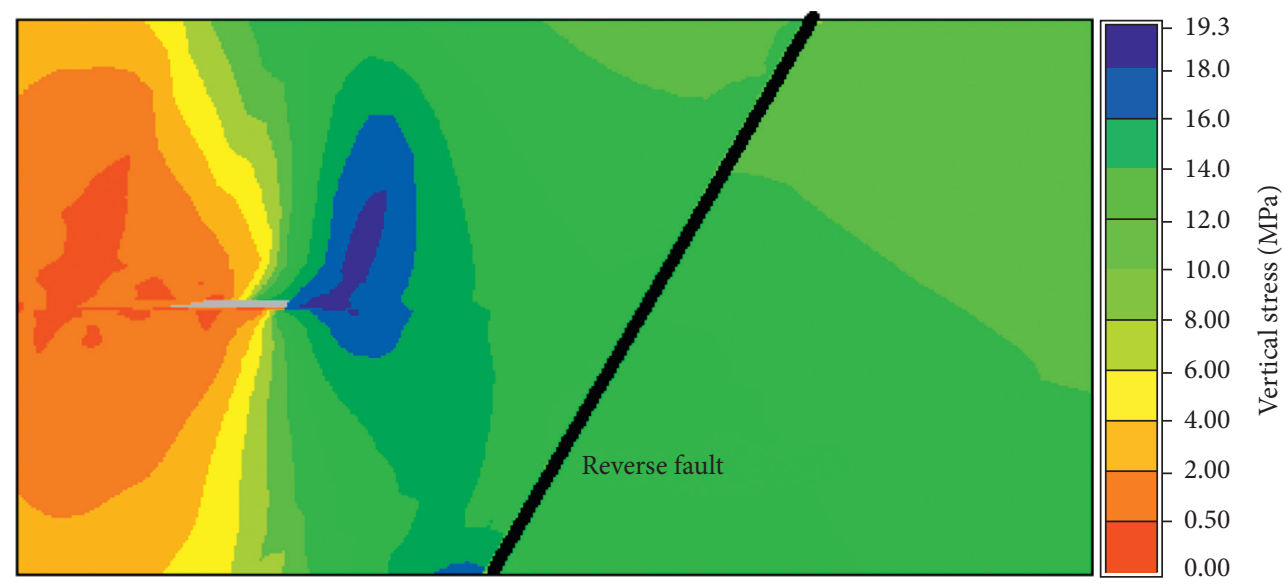

(b)

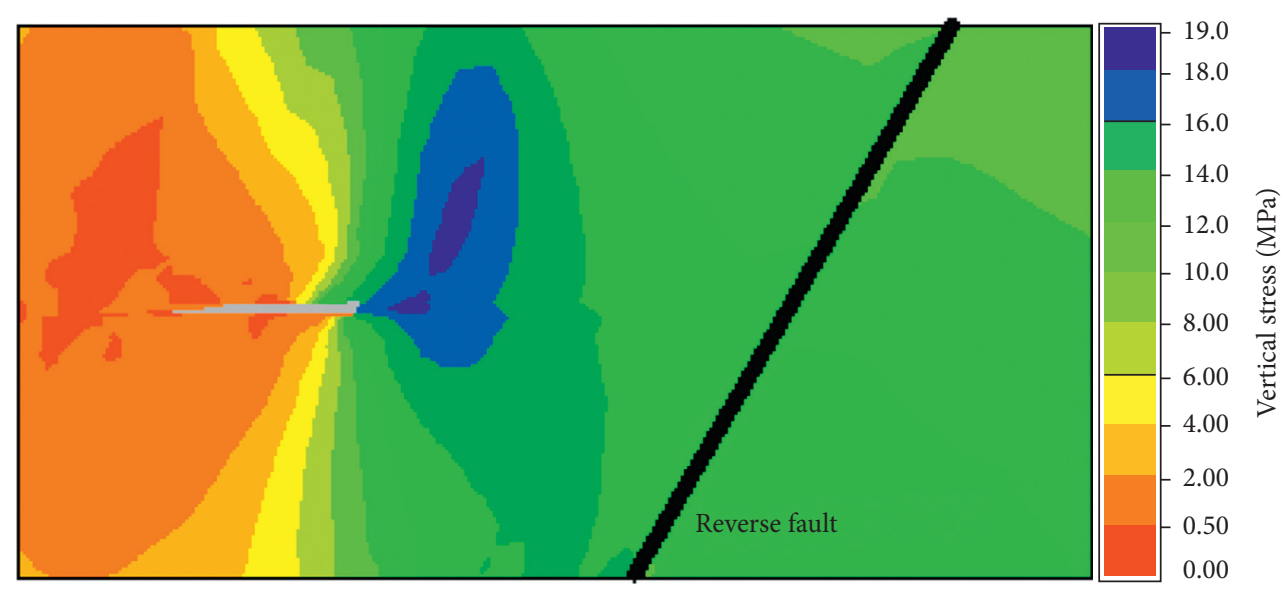

(c)

Figure 13: Continued. 

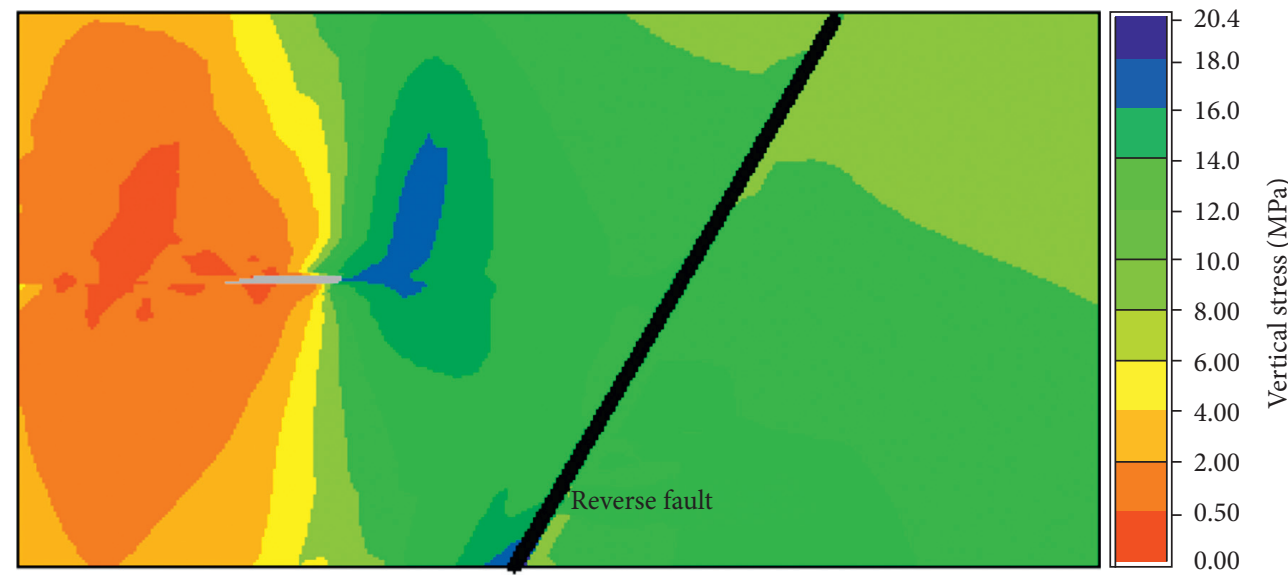

(d)

Figure 13: Stress distribution when the distance between working face and reverse fault is $40 \mathrm{~m}$ with different fault throw. (a) The throw of reverse fault is $4 \mathrm{~m}$. (b) The throw of reverse fault is $10 \mathrm{~m}$. (c) The throw of reverse fault is $15 \mathrm{~m}$. (d) The throw of reverse fault is $20 \mathrm{~m}$.

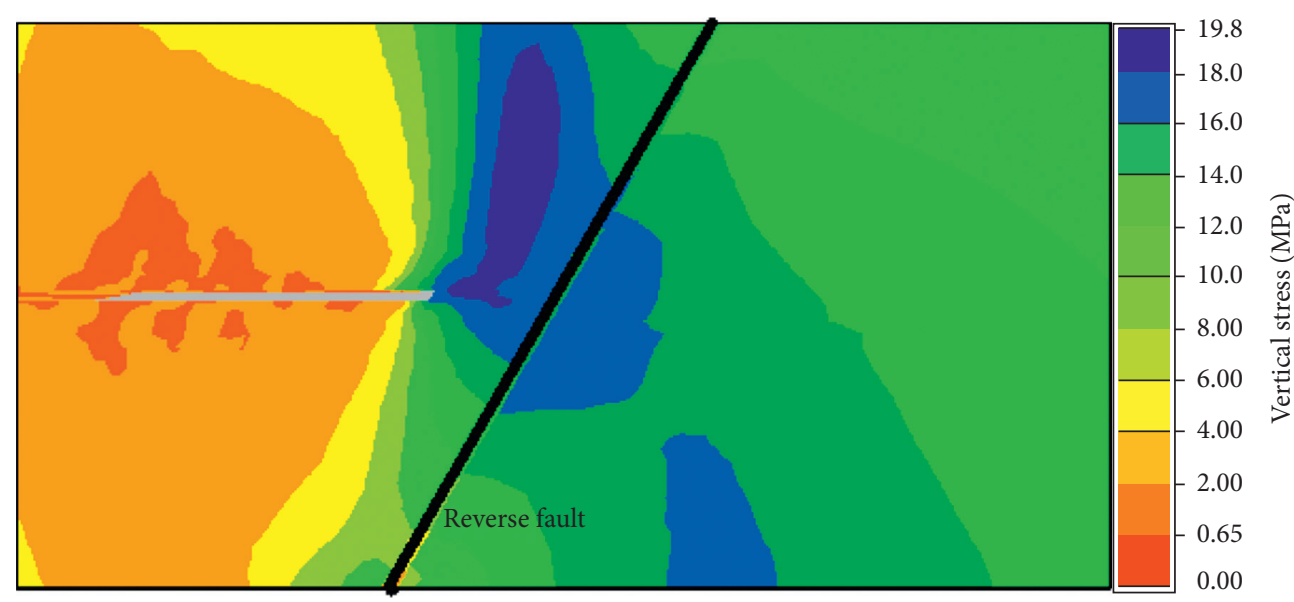

(a)

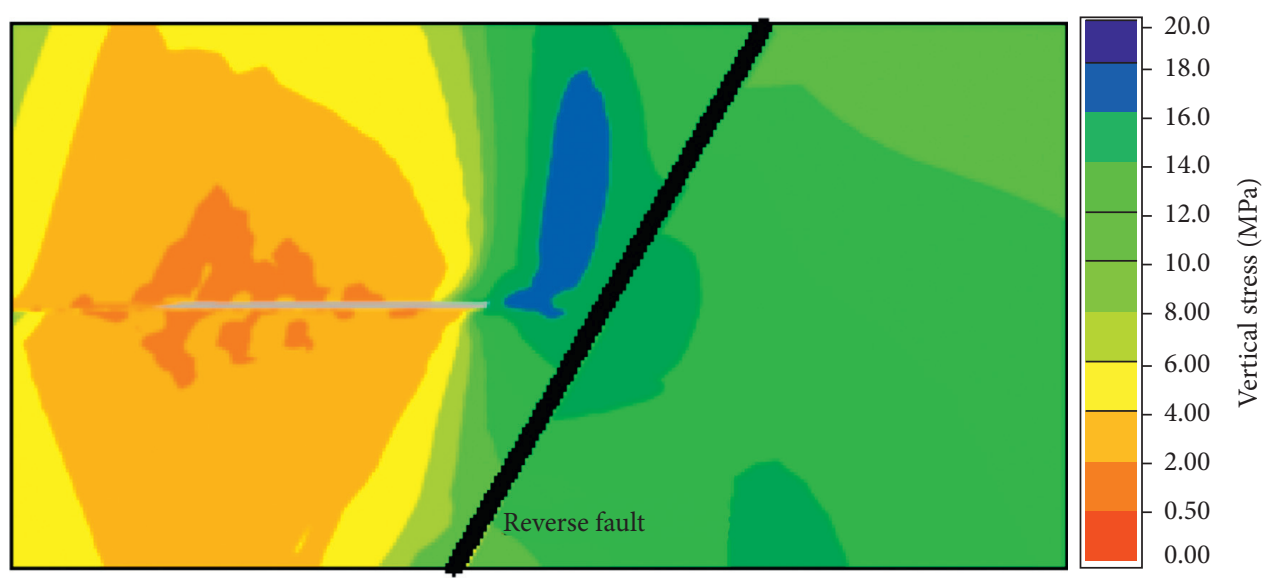

(b)

Figure 14: Continued. 


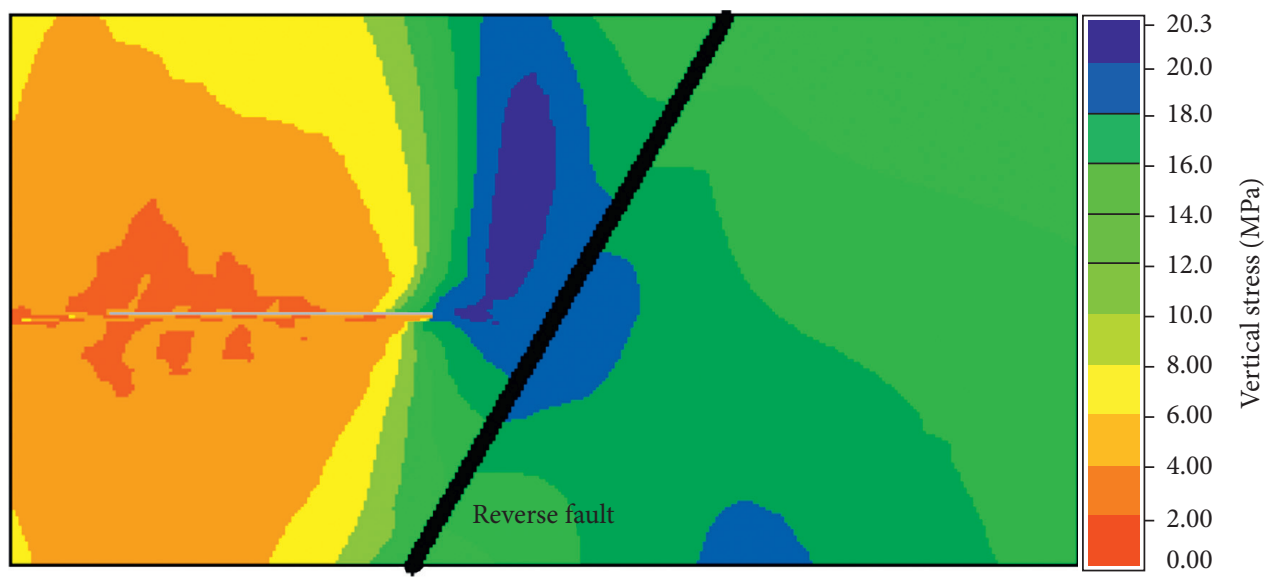

(c)

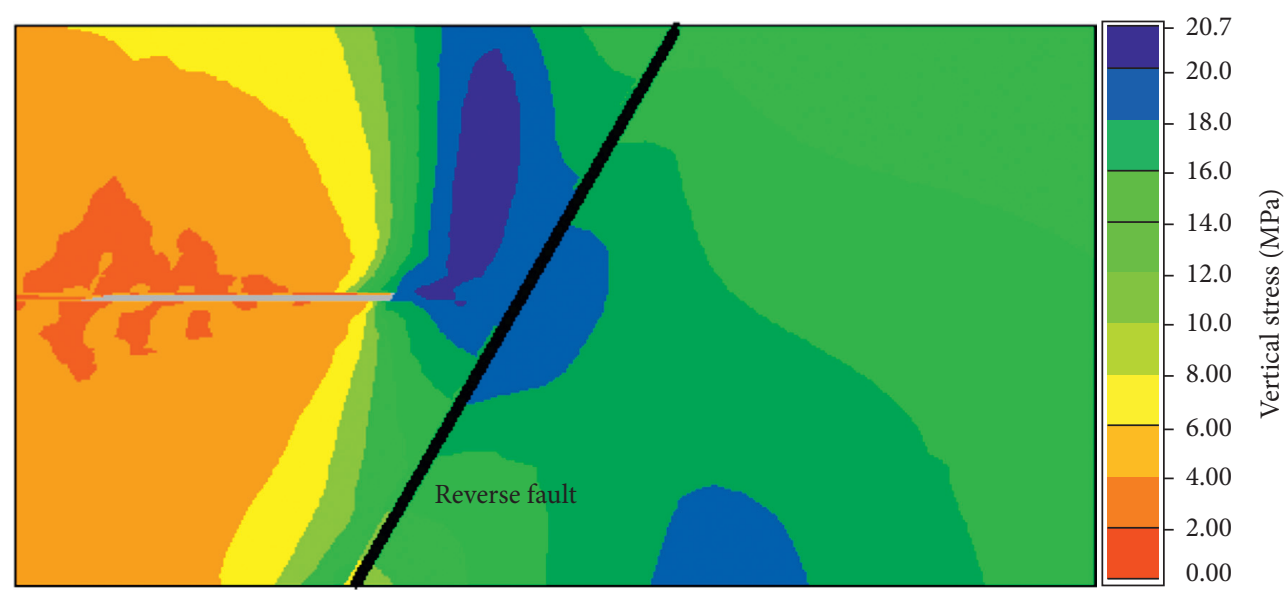

(d)

Figure 14: Stress distribution when the distance between working face and reverse fault is $10 \mathrm{~m}$ with different fault throw. (a) The throw of reverse fault is $4 \mathrm{~m}$. (b) The throw of reverse fault is $10 \mathrm{~m}$. (c) The throw of reverse fault is $15 \mathrm{~m}$. (d) The throw of reverse fault is $20 \mathrm{~m}$.

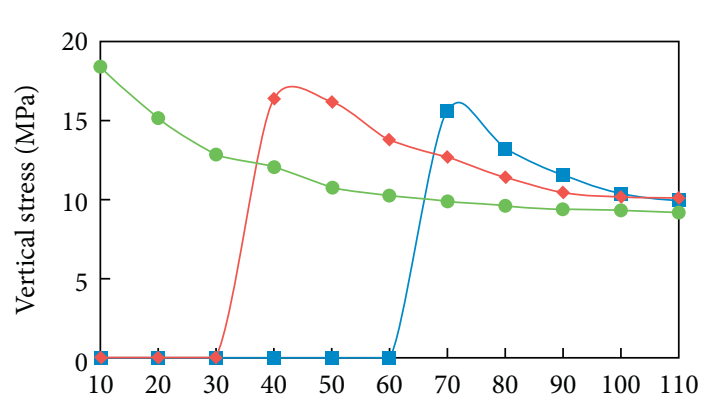

Distance between working face and reverse fault $(\mathrm{m})$

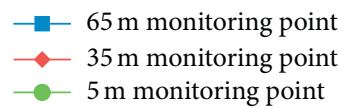

(a)

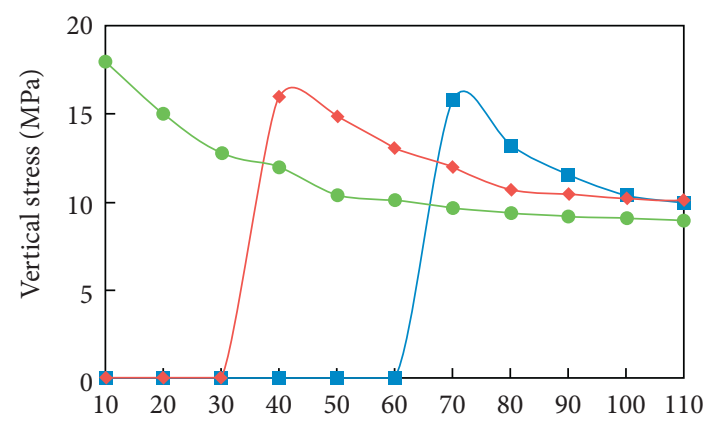

Distance between working face and reverse fault $(\mathrm{m})$

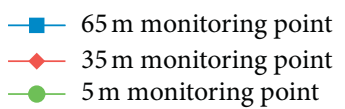

(b)

Figure 15: Continued. 


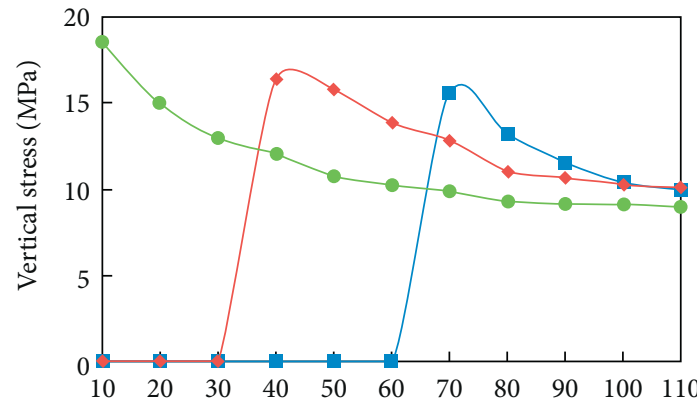

Distance between working face and reverse fault $(\mathrm{m})$ $\longrightarrow 35 \mathrm{~m}$ monitoring point
$-5 \mathrm{~m}$ monitoring point

(c)

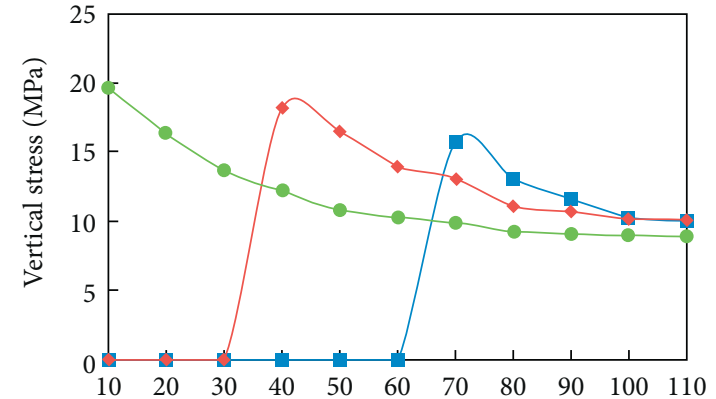

Distance between working face and reverse fault $(\mathrm{m})$

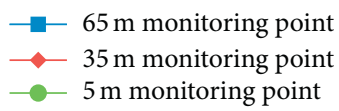

(d)

FIGURE 15: Variation curve of the vertical stresses at the monitoring points with different fault throw. (a) The throw of reverse fault is $4 \mathrm{~m}$. (b) The throw of reverse fault is $10 \mathrm{~m}$. (c) The throw of reverse fault is $15 \mathrm{~m}$. (d) The throw of reverse fault is $20 \mathrm{~m}$.

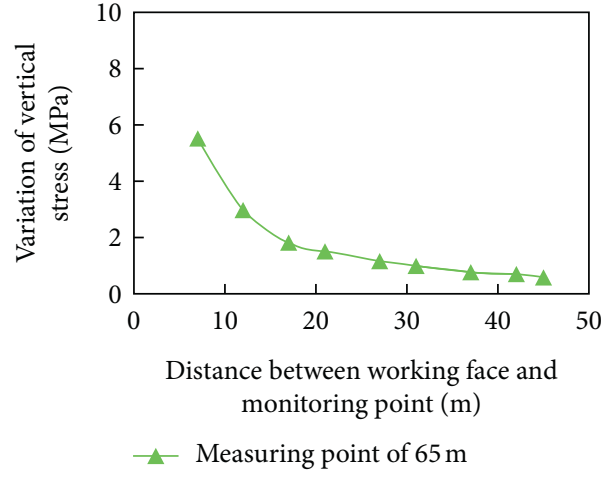

(a)

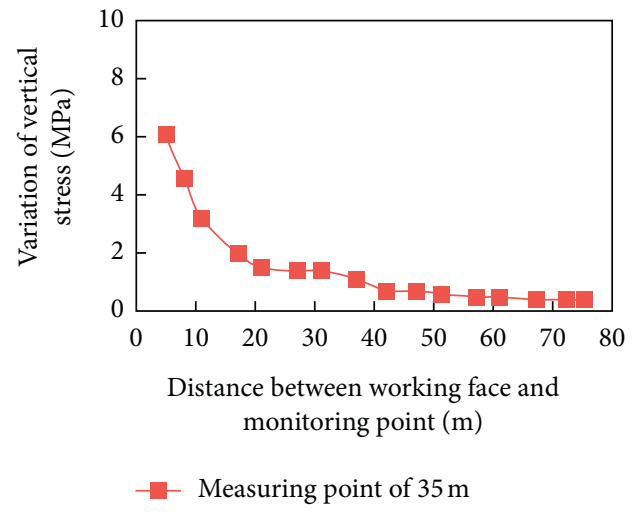

(b)

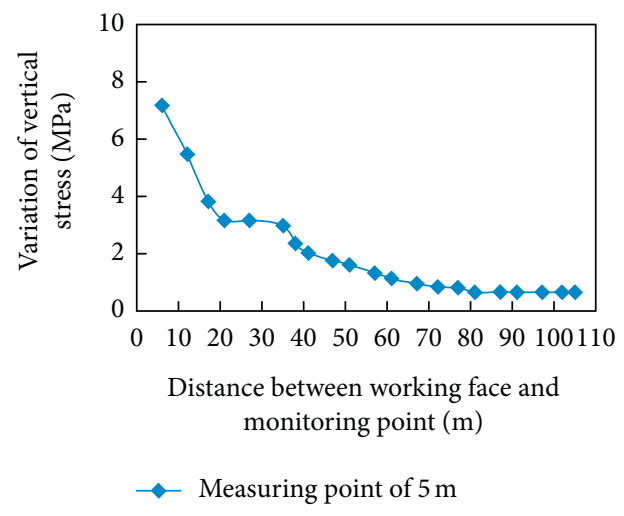

(c)

FiguRE 16: Borehole stress with working face advancing in Xinchun coal mine. (a) Change of coal stress at $65 \mathrm{~m}$ monitoring point. (b) Change of coal stress at $35 \mathrm{~m}$ monitoring point (c) Change of coal stress at $5 \mathrm{~m}$ monitoring point. 


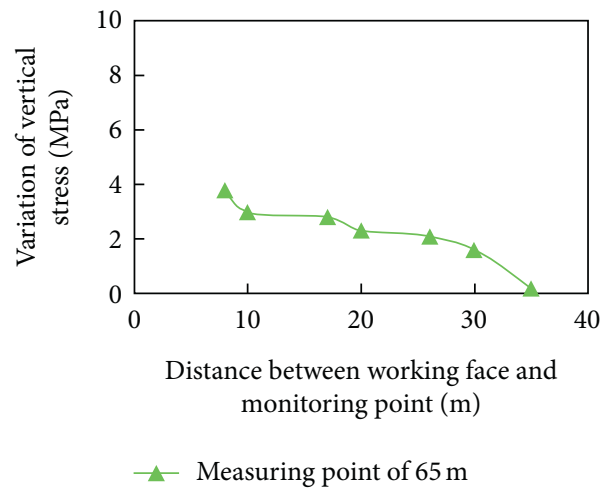

(a)

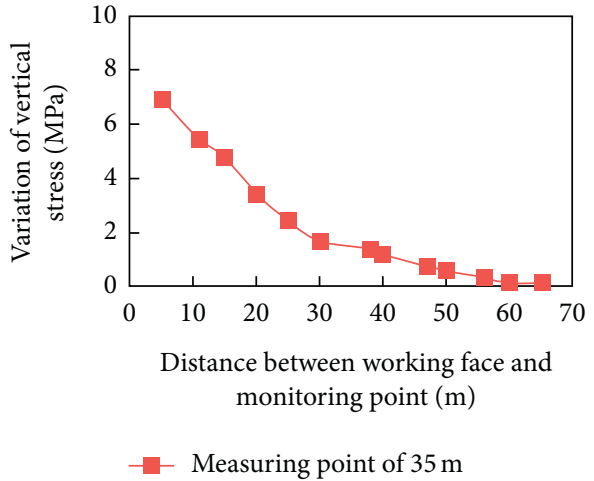

(b)

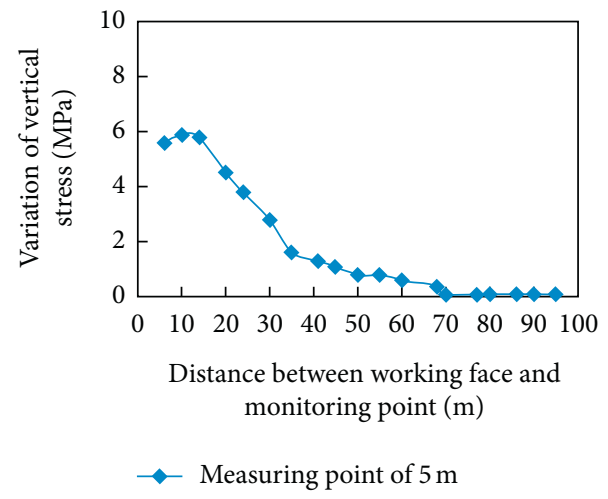

(c)

Figure 17: Borehole stress with working face advancing in ZuoQiuka coal mine. (a) Change of coal stress at $65 \mathrm{~m}$ monitoring point. (b) Change of coal stress at $35 \mathrm{~m}$ monitoring point (c) Change of coal stress at $5 \mathrm{~m}$ monitoring point.

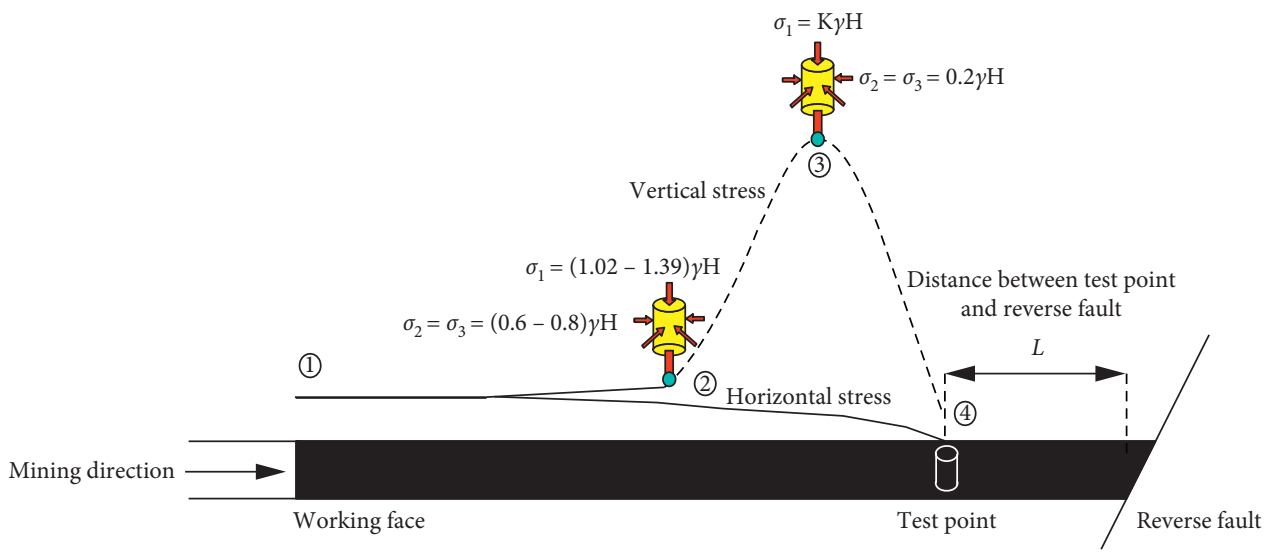

FIGURE 18: Stress change of coal in reverse fault area under dynamic influence.

exceeds its strength, causing the coal body to fail and lose its load-bearing capacity, leading to the decrease in the stress concentration coefficient $K$.

\section{Conclusions}

(1) The mechanical analysis model of reverse fault-affected mined coal body was established, the coal stress characterization equation was derived, the coal stress distribution was calculated, and the
Mohr-Coulomb strength criterion was applied to analyze the stability of the coal body. It could be inferred that the closer it gets to the reverse fault, the poorer is the stability of the coal body and that the stress concentration magnitude of the mined coal body is affected by the strength of the coal body.

(2) FLAC $^{3 D}$ was used to study the stress variation trend of the mined coal body, and the accuracy of coal body stress calculated by the mechanical model was verified. It is concluded that in case of hanging-wall 
mining, the stress concentration of the mined coal body decreases with the increase of reverse fault dip angle and increases with the increase of reverse fault throw. Also, the stress concentration magnitude in the case of footwall mining is less than that of hanging-wall mining. The choice to mine the hanging wall or footwall and the parameters of reverse fault affect the stress concentration magnitude of the coal body. At the same time, combined with the field monitoring results of the coal body stress measured by intrinsically safe GZY 25 borehole stress sensors, it has been verified that the coal body stress concentration magnitude may either increase or decrease, depending on the actual conditions.

(3) Based on theoretical analysis, numerical simulation, and field test results, when the mining activity on the working face proceed towards the reverse fault, the vertical stress of the coal body initially demonstrates a significant rise as the distance from the reverse fault lessens. At any point during this stage, the vertical stress can be generalized as (1.02-1.39) $\gamma \cdot H$. Going into the latter stage, once the test point falls on the stress concentration area in front of the working face, the vertical stress will reach its maximum, which can be acquired by $K \cdot \gamma \cdot H$. Moreover, the stress concentration coefficient $K$ is related to the distance $L$ from the reverse fault, and two kinds of changes may take place. Firstly, if the coal-bearing capacity does not exceed its strength, the coal stress in front of the working face, and hence the stress concentration coefficient of the mined coal body, will increase gradually. Secondly, the stress concentration magnitude of mining coal body gradually increases first, before decreasing after the coal body bearing capacity exceeds its strength, during which the coal body experiences structural failure and loses its loadbearing capacity, ultimately resulting in the decline of the stress concentration coefficient.

\section{Data Availability}

The data used to support the findings of this study are available from the corresponding author upon request.

\section{Conflicts of Interest}

The authors declare that there are no conflicts of interest regarding the publication of this paper.

\section{Acknowledgments}

This work was supported by the National Key R\&D Program of China (no. 2018YFC0807900), the Science and Technology Innovation Project of China Coal Technology and Engineering Group (no. 2018-2-MS022), and the Science and Technology Innovation Project of China Coal Technology and Engineering Group (no. 2018QN010).

\section{References}

[1] Y. Cao, Coal Mine Geology, China University of Mining and Technology Press, Xuzhou, China, 2014.

[2] X. Chen, W. Li, and X. Yan, "Analysis on rock burst danger when fully-mechanized caving coal face passed fault with deep mining," Safety Science, vol. 50, no. 4, pp. 645-648, 2012.

[3] J.-F. Ritz, S. Baize, M. Ferry et al., "Surface rupture and shallow fault reactivation during the $2019 \mathrm{Mw} 4.9$ Le Teil earthquake, France," Communications Earth \& Environment, vol. 1, no. 1, 2020.

[4] Y. Li and R. Zhou, "Analysis of mechanical characteristics and instability law of inverse fault under the influence of mining," Earth Sciences Research Journal, vol. 22, no. 2, pp. 139-144, 2018.

[5] S. Dalgiç, "Tunneling in fault zones, Tuzla tunnel, Turkey," Tunnelling and Underground Space Technology Incorporating Trenchless Technology Research, vol. 18, no. 5, pp. 453-465, 2003.

[6] H. O. Safari, S. Pirasteh, B. Pradhan, and H. Amid, "Geohazards analysis of Pisa tunnel in a fractured incompetent rocks in Zagros Mountains, Iran," Arabian Journal of Geosciences, vol. 6, no. 4, pp. 1101-1112, 2013.

[7] S. Husen, E. Kissling, and A. V. Deschwanden, "Induced seismicity during the construction of the Gotthard Base Tunnel, Switzerland: hypocenter locations and source dimensions," Journal of Seismology, vol. 11, no. 1, pp. 19-28, 2013.

[8] W. Schubert, A. Fasching, and A. Goricki, "Tunnelling in fault zones-state of the art," Tunnelling and Underground Space Technology, vol. 21, no. 3-4, pp. 376-377, 2006.

[9] H. Moulouel, A. Bouchelouh, R. Bensalem et al., "The Mahelma fault: a secondary structure of the Sahel anticline?" Arabian Journal of Geosciences, vol. 13, no. 15, 2020.

[10] M. Ranjbarnia, M. Zaheri, and D. Dias, "Three-dimensional finite difference analysis of shallow sprayed concrete tunnels crossing a reverse fault or a normal fault: a parametric study," Frontiers of Structural and Civil Engineering, vol. 14, pp. 998-1011, 2020.

[11] M. Sabagh and A. Ghalandarzadeh, "Centrifuge experiments for shallow tunnels at active reverse fault intersection," Frontiers of Structural and Civil Engineering, vol. 14, pp. 731-745, 2020.

[12] L. Zhao, X. Shen, C. Geng, and X. Hu, "Analysis and solution of abnormal fault of data storage based on NAND-flash," Science Discovery, vol. 8, no. 4, 2020.

[13] Y. Fukushima and N. Ghayournajarkar, "Determination of the dipping direction of a blind reverse fault from InSAR: case study on the 2017 sefid sang earthquake, northeastern Iran," Earth Planets and Space, vol. 72, no. 1, p. 15, 2020.

[14] M. Fadaee, F. Farzaneganpour, and I. Anastasopoulos, "Response of buried pipeline subjected to reverse faulting," Soil Dynamics and Earthquake Engineering, p. 132, 2020.

[15] E. Wang, Q. Shao, Y. Du et al., "Genesis mechanism and distribution of structural coal on two sides of reverse fault," Mining Safety \& Environmental Protection, vol. 37, no. 1, pp. 4-6, 2010.

[16] M. Qian, P. Shi, and J. Xu, Mine Pressure and Rock Strata Control, China University of Mining and Technology Press, Xuzhou, China, 2010.

[17] C. Liang, Research on Failure Strain and Permeability Evolution of the Coal Ahead of Working Face and Its Application, China University of Mining and Technology, Beijing, China, 2016. 
[18] J. Jiang, Q. Wu, and H. Qu, "Mining stress evolution and fault activation characteristics of reverse faults under hard and thick strata," Journal of Coal Science, vol. 36, no. 7, pp. 1067-1074, 2011.

[19] J. Jiang, Q. Wu, and Q. Hua, "Evolutionary characteristics of mining stress near the hard-thick overburden normal faults," Journal of Mining and Safety Engineering, vol. 31, no. 6, pp. 881-887, 2014.

[20] H. Xie, H. Gao, J. Liu et al., "Study on mining dynamic behavior under different mining conditions," Journal of Coal Science, vol. 36, no. 7, pp. 1067-1074, 2011. 